\title{
A influência de estruturas preexistentes na formação de riftes oblíquos: o uso da modelagem física e sua comparação com a fase Pré-sal da Bacia de Santos, Brasil
}

\author{
The influence of pre-existing structures in oblique rifting formation: The use of physical \\ modeling and comparison with the pre-salt phase of Santos Basin, Brazil
}

\author{
Carlos Eduardo Lourenço Pereira ${ }^{1}$ (1), Caroline Janette Souza Gomes ${ }^{1}$ (1), Mario Neto Cavalcanti de Araujo ${ }^{2}$ (1) \\ ${ }^{1}$ Universidade Federal de Ouro Preto - UFOP, Departamento de Geologia, Campus da Universidade Federal de Ouro Preto, \\ Morro do Cruzeiro, CEP: 35400-000, Ouro Preto, MG, BR (carlos_lpereira@hotmail.com; caroline.janette@gmail.com) \\ ${ }^{2}$ Centro de Pesquisas Leopoldo Américo Miguez de Mello - Cenpes, Petrobras, Rio de Janeiro, RJ, BR \\ (mario_araujo@petrobras.com.br)
}

Recebido em 9 de fevereiro de 2021; aceito em 20 de outubro de 2021

\begin{abstract}
Resumo
A evolução de riftes oblíquos é analisada neste artigo pela realização de modelos físicos, em escala. O intuito foi analisar a fase rifte da Bacia de Santos, examinando a influência da estrutura preexistente do embasamento. Para refinar as informações obtidas, empregou-se a tecnologia particle image velocimetry. Desenvolveram-se três experimentos em caixas de acrílico, com dimensões internas de $37 \mathrm{~cm} \mathrm{x} 41 \mathrm{~cm}$ x $07 \mathrm{~cm}$ (largura x comprimento x altura), empregando-se areia e silicone para crosta rúptil e dúctil, respectivamente. A estrutura foi simulada por duas folhas de acetato, na base da caixa de experimentos, constituídas de quatro domínios estruturais. A abertura do rifte ortogonal a oblíqua em relação à estrutura preexistente foi efetuada por duas paredes móveis. Os resultados revelaram que a estruturação de riftes é influenciada tanto pela configuração da estrutura preexistente quanto pela direção da extensão. Os dois modelos cujos domínios estruturais formavam ângulos de obliquidade com a direção da extensão menores que $90^{\circ}$ produziram falhas com dimensões curtas a intermediárias, grande número de rampas de revezamento e zonas de acomodação. Já o modelo com os domínios estruturais formando ângulos de obliquidade próximos a $90^{\circ}$ gerou falhas contínuas, longas, quase retas e nenhuma zona de acomodação. Nesse modelo, as falhas revelaram a maior magnitude de deformação. Nos dois primeiros modelos, ainda se destacaram um alto estrutural entre duas sub-bacias dispostas en echelon e a mudança de direção das falhas quando estas passavam de um domínio a outro. A configuração definiu uma geometria em S muito parecida com aquela da porção centro-norte da Bacia de Santos.
\end{abstract}

Palavras-chave: Modelagem física analógica; Estrutura preexistente; Extensão oblíqua e ortogonal; Bacia de Santos.

\begin{abstract}
Physical modelling was employed to analyze the evolution of oblique rifting in this article. The objective was to analyze the rift phase of the Santos Basin, by observing the influence of the pre-existing basement structure. To refine resulting data, we used the PIV (Particle Image Velocimetry) technique. Three experiments were carried out in acrylic boxes, with internal dimensions of $37 \times 41 \times 07 \mathrm{~cm}$ (width $\times$ length $\times$ height), using sand and silicone to represent brittle and ductile crust, respectively. The structure was simulated by two acetate sheets, at the base of the experiment box, sorted into four structural domains. Orthogonal and oblique rift opening to the pre-existing structure was created by moving two mobile walls. The results revealed that forming rift structures are influenced both by the geometry of underlying pre-existing structures and extension direction. The two models with structural domains forming obliquity angles smaller than $90^{\circ}$ to the extension direction produced short and intermediate faults, many relay ramps and accommodation zones. However, the model with structural domains forming obliquity angles close to $90^{\circ}$, showed continuous, long, nearly straight faults and no accommodation zones. In this model, the faults had the greatest deformation magnitude. In the first two models, a prominent structural high is observed between two en-echelon sub-basins, along with change in faults direction as they transition from one domain to another. A 'S' geometry was formed, in similar fashion to that observed in the north-central portion of the Santos Basin.
\end{abstract}

Keywords: Physical analog modeling; Pre-existing structure; Oblique and orthogonal extension; Santos Basin 


\section{INTRODUÇÃO}

O entendimento das estruturas do rifte e da evolução tectônica da margem continental do Atlântico Sul é de suma importância para a exploração e o desenvolvimento de campos de petróleo em águas ultraprofundas. Nesse contexto, destaca-se a Bacia de Santos (Figura 1), cujas principais descobertas estão relacionadas à existência de hidrocarbonetos em reservatório da fase rifte, conhecidos como o Pré-sal Brasileiro. O Pré-sal é definido como uma acumulação de hidrocarbonetos em reservatórios carbonáticos fortemente associados a altos estruturais da seção rifte (Carminatti et al., 2008; Carlotto et al., 2017; Minzoni et al., 2019).

Nos primeiros estágios da formação de uma margem rifteada, as heterogeneidades preexistentes apresentam grande influência na evolução e segmentação do rifte (Dunbar e Sawyer, 1989; Ring, 1994; Tommasi e Vauchez, 2001; Taylor et al., 2011; Gerya, 2012; Fossen et al., 2016; Zwaan e Schreurs, 2017; Stanton et al., 2019). Essas heterogeneidades são geralmente formadas por contrastes litológicos ou zonas de cisalhamento resultantes de estágios de deformação prévias, que podem ocorrer com larguras quilométricas. A segmentação de um sistema distensional é produzida pela distribuição heterogênea de falhas normais individuais ou sistemas de falhas. A evolução do rifte envolve a interação entre esses segmentos resultando em rampas de revezamento (Peacock e Sanderson, 1991; Morley, 1995; Larsen, 1998; Peacock et al., 2000; Fossen e Rotevatn, 2016; Bubeck et al., 2017; Nixon et al., 2019) e, em uma escala mais ampla, em zonas de acomodação e transferência (Gibbs, 1984; Rosendahl, 1987; Morley et al., 1990; Faulds e Varga, 1998; Zwaan et al., 2018; La Rosa et al., 2019; Maestrelli et al., 2020). Existem vários exemplos de regiões caracterizadas por riftes segmentados e interligados por zonas de acomodação e transferência, no mundo, com destaque para o Graben Viking do Mar do Norte (Fossen et al., 2010; Zhong e Escalona, 2020), Canyonlands, em Utah, Estados Unidos (Trudgill e Cartwright, 1994; Fossen et al., 2010; Fossen e Rotevatn, 2016), o Golfo de Suez (McClay et al., 1998; Gamal et al., 2021) e o rifte do Leste Africano (Morley et al., 1990; Corti, 2012; Corti et al., 2019; Scholz et al., 2020).

Apesar do processo de distensão da crosta no Atlântico Sul envolver inúmeras incertezas, é amplamente aceito que a abertura teria ocorrido em uma direção aproximada E-W (Mohriak et al., 2002; Torsvik et al., 2009; Moulin et al., 2010). Muitos autores interpretam fortes componentes direcionais

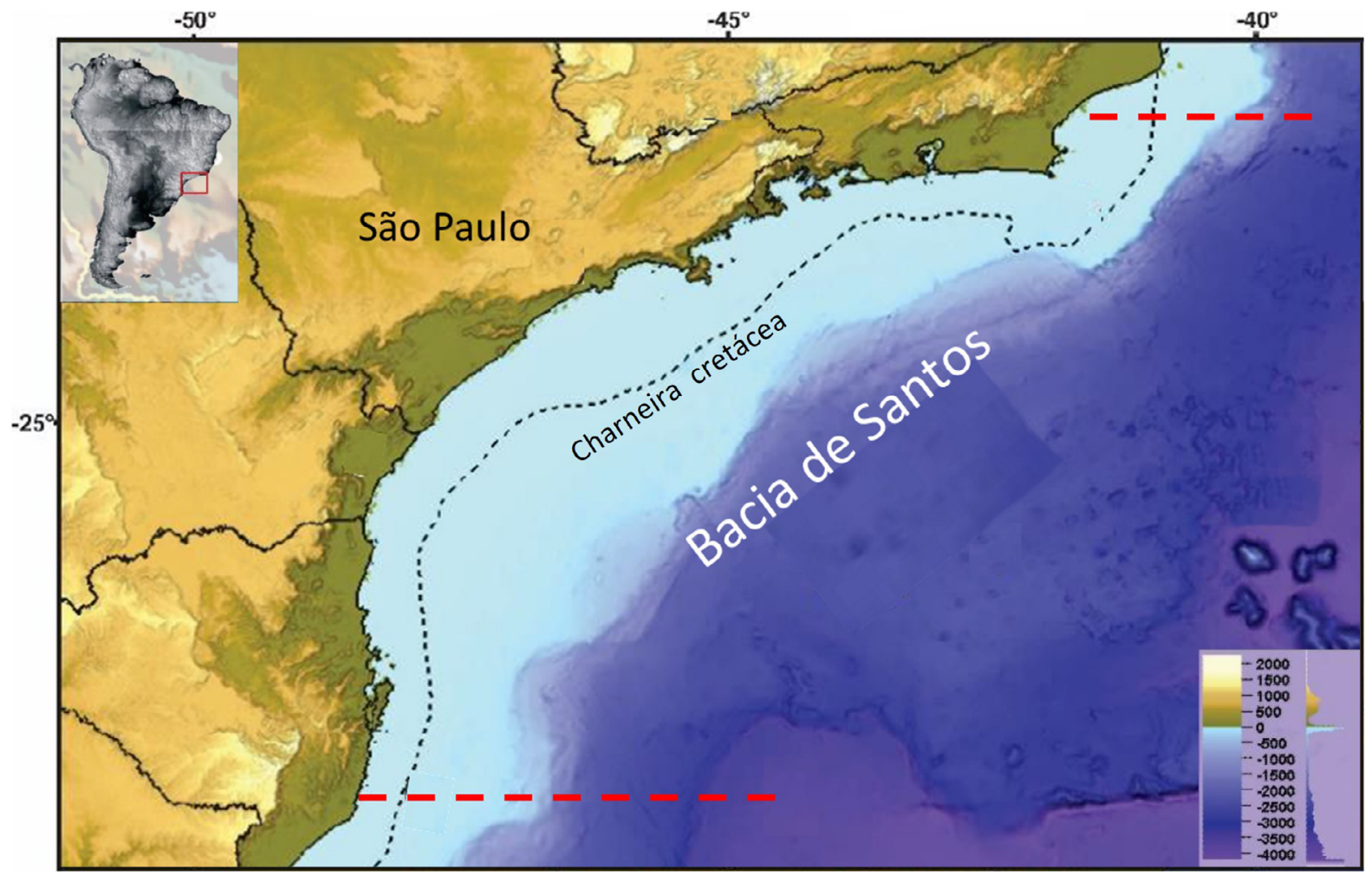

Fonte: modificada de Sandwell e Smith (2009).

Figura 1. Mapa de localização da Bacia de Santos (topo batimétrico). As linhas tracejadas em vermelho representam a área de estudo do presente trabalho. 
de deslocamento em razão do ângulo oblíquo entre a direção da extensão e as falhas preexistentes, de direção geral NE-SW (Macedo, 1990; Pereira e Macedo, 1990; Cobbold et al., 2001; Meisling et al., 2001). Em consequência, cada região da bacia tem uma configuração estrutural diferente, sendo a posição dos altos estruturais o fator dominante na distribuição das melhores regiões do reservatório no Présal (Gomes et al., 2012).

No presente trabalho, empregou-se a modelagem física analógica visando contribuir para o entendimento do processo deformacional da Bacia de Santos. O objetivo era analisar a influência de uma estrutura prévia sobre a evolução do rifte e examinar a formação de altos estruturais, a segmentação do rifte e o desenvolvimento de rampas de revezamento e zonas de acomodação. Com esse intuito, desenvolveram-se modelos experimentais aplicando-se três ângulos diferentes de extensão. A técnica particle image velocimetry (PIV) (por exemplo, Adam et al., 2005; Van Gent et al., 2010), que constitui um monitoramento ótico de partículas, foi usada para analisar as magnitudes de deformação em cada experimento.

\section{BACIA DE SANTOS}

A formação da Bacia de Santos (Figura 1) está associada aos múltiplos processos de rifteamento do paleocontinente Gondwana, no Eocretáceo. O embasamento da área estudada é composto de rochas pertencentes à Faixa Ribeira que fazem parte do sistema orogênico Neoproterozoico-Cambriano de direção NE-SW (Heilbron et al., 2000, 2008; Schmitt et al., 2016). De acordo com Moreira et al. (2007), a evolução tectono-sedimentar da Bacia de Santos pode ser dividida em três fases: rifte, pós-rifte e drifte. A fase rifte resultou de esforços distensionais que culminaram na separação das placas Sul-Americana e Africana. A tectônica extensional gerou o espaço necessário para a acomodação de depósitos sedimentares, sendo a subsidência mecânica responsável pela formação e reativação de falhas normais (Moreira et al., 2007). A fase pós-rifte caracterizou-se por um contínuo aprofundamento da bacia sob domínio tectônico termal com um aumento gradual de incursões marinhas. Pela presença de barreiras vulcânicas (por exemplo, o Alto de Florianópolis), que restringiram a circulação da água marinha, associada ao clima quente, às altas taxas de evaporação e à salinidade da água, ocorreu a deposição de espessos pacotes evaporíticos com mais de $2 \mathrm{~km}$ de espessuras (Szatmari e Milani, 2016). A fase drifte conduziu à individualização das placas Sul-Americana e Africana, caracterizando a transição de crosta oceânica para crosta continental (Mohriak, 2003) e determinando o término da bacia evaporítica. A subsequente subsidência termal ocasionou o aprofundamento da bacia com a instalação de um pleno oceano e a deposição de sedimentos carbonáticos e, posteriormente, siliciclásticos (Gamboa et al., 2008).

As estruturas da Bacia de Santos são compostas sobretudo de um sistema principal de falhas normais com mergulhos sintéticos para SE e orientação paralela à linha de costa, aproximadamente NE-SW, com inflexões na direção E-W e N-S (Figura 2). Heterogeneidades do embasamento controlaram a arquitetura das principais estruturas dos sistemas riftes da bacia, formando altos estruturais intrabacinais. A charneira do Cretáceo (Kumar e Gamboa, 1979; Macedo, 1990; Pereira e Macedo, 1990) é uma importante estrutura do embasamento, que separa a bacia em duas porções distintas: uma parte, interna, mais rasa e outra, externa, mais profunda (Alves, 2002). A charneira está relacionada com o início da formação do rifte, de idade hautereviana (130 Ma) (Moreira et al., 2007). Durante a fase rifte, a extensão da crosta continental conduziu à geração de importantes zonas ou faixas de transferências (Figura 2). Essas zonas tiveram forte influência na configuração final da geometria da bacia, ocasionando as abruptas mudanças de direção das estruturas ao longo da bacia.

\section{O MÉTODO EXPERIMENTAL}

\section{Os materiais análogos e a escala}

Nos experimentos analógicos, utilizaram-se areia e silicone para representar o comportamento reológico da crosta superior e inferior, respectivamente. A areia é reconhecida como um excelente análogo para a simulação de bacias sedimentares dado seu comportamento mecânico similar aos das rochas crustais (Mandl, 1987; Krantz, 1991; Schellart, 2000; McClay et al., 2002; Eisenstadt e Sims, 2005; Zwaan e Schreurs, 2017). Medidas de laboratório (Carvalho, 2017) indicam que a areia utilizada possui densidade $\rho=1,50 \mathrm{~g} /$ $\mathrm{cm} 3$ e um ângulo de atrito interno de $\phi=38,77^{\circ}$ e $36,68^{\circ}$, para as areias colorida e não colorida, respectivamente. Além disso, a areia rompe de acordo com o critério de CoulombMohr, independentemente da taxa de deformação, e possui baixa coesão (McClay e Ellis, 1987; Vendeville et al., 1987). O silicone utilizado nos experimentos foi o polydimethylsiloxane, da firma Clearco, que possui comportamento newtoniano quase perfeito (Weijermars e Schmeling, 1986) e viscosidade $\eta=2 \times 10^{4}$ Pa.s e densidade $\rho=0,97 \mathrm{~g} / \mathrm{cm} 3$, conforme informada pelo fabricante.

Posto que os modelos análogos simulam em pequena escala fenômenos físicos de grandes dimensões, os experimentos devem estar propriamente escalados. Os exemplos naturais e os modelos analógicos devem possuir similaridades geométricas, cinemáticas e dinâmicas conforme a teoria da similaridade de Hubbert (1937). A Tabela 1 apresenta os parâmetros usados nos experimentos e respectivos 


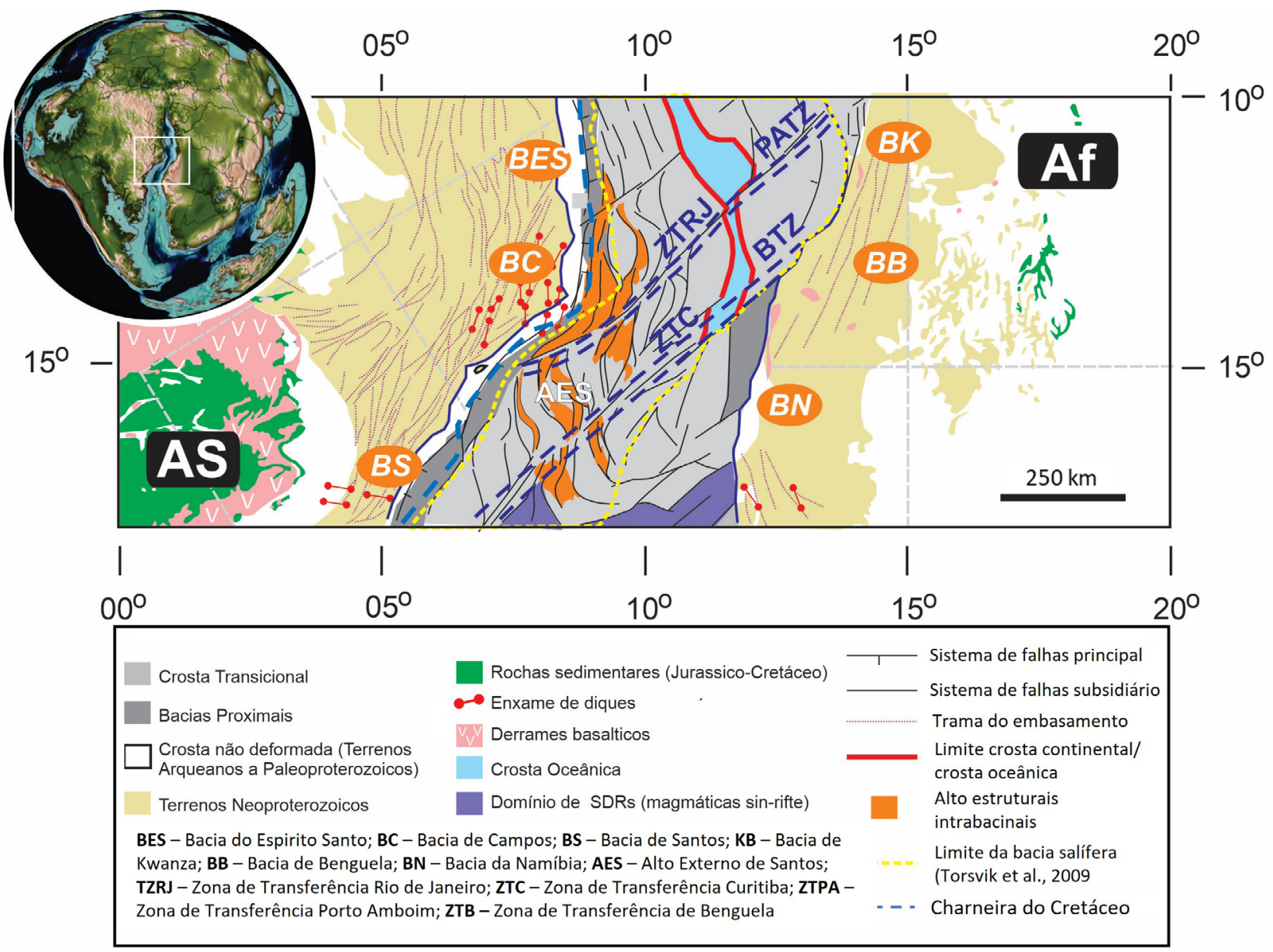

Fonte: modificada de Morgan et al. (2020).

Figura 2. Reconstrução de placas para $117 \mathrm{Ma}$, inspirada nos trabalhos de Heine et al. (2013) e Torsvik et al. (2009), ilustrando os principais elementos estruturais intrabacinais entre as bacias do Espírito Santo e Santos, bem como suas conjugadas no lado africano. Notar que o continente africano (Af) está fixo, com respeito ao continente sul-americano móvel (AS). Siglas referentes às zonas de transferência foram adotadas conforme os trabalhos de Guiraud et al. (2010).

Tabela 1. Principais parâmetros físicos com os respectivos fatores de escala.

\begin{tabular}{|c|c|c|c|}
\hline Parâmetros & Valores no modelo & Valores na Natureza & $\begin{array}{l}\text { Razão modelo / } \\
\text { Natureza }\end{array}$ \\
\hline Comprimento (L) & $0,01 \mathrm{~m}$ & $10^{4} \mathrm{~m}$ & $L^{*}=10^{-6}$ \\
\hline Densidade $\left(\rho_{1}\right)$ : crosta superior & $1.500 \mathrm{~kg} / \mathrm{m}^{3}$ & $2.600-2.800 \mathrm{~kg} / \mathrm{m}^{3(a, b)}$ & $\rho_{1}^{*}=0,57$ \\
\hline Densidade $\left(\rho_{2}\right)$ : crosta inferior & 970 kg/m³ & $2.900 \mathrm{~kg} / \mathrm{m}^{3(a, b)}$ & $\rho_{2}{ }^{*}=0,33$ \\
\hline Gravidade (g) & $9,81 \mathrm{~m} / \mathrm{s}^{2}$ & $9,81 \mathrm{~m} / \mathrm{s}^{2}$ & $g^{\star}=1$ \\
\hline $\begin{array}{l}\text { Viscosidade }(\mu=\sigma / \epsilon)) \text { (crosta } \\
\text { inferior) }\end{array}$ & $2 \times 10^{4}$ Pa.s & $10^{21(a, b)}$ Pa.s & $\eta^{*}=2 \times 10^{-17}$ \\
\hline Tensão ( $\sigma=\rho \mathrm{g} \mathrm{L})$ & - & - & $\sigma^{\star}=\rho^{*} g^{\star} L^{\star}=3,34 x$ \\
\hline Taxa de deformação $(\dot{\varepsilon})$ & - & - & $\dot{\varepsilon}^{\star}=\sigma^{\star} / \eta^{*}=1,67 \times 10^{10}$ \\
\hline Velocidade (v) & $\begin{array}{c}8,3 \times 10^{-6} \mathrm{~m} / \mathrm{s} \\
(3 \mathrm{~cm} / \mathrm{h})\end{array}$ & $\begin{array}{c}48 \times 10^{-11} \mathrm{~m} / \mathrm{s} \\
(15 \mathrm{~m} / \mathrm{a})\end{array}$ & $V^{\star}=\epsilon^{\star} L^{\star}=1,75 \times 10^{4}$ \\
\hline
\end{tabular}

aAutin et al. (2013); 'Wwaan e Schreurs (2017). 
fatores de escala. Utilizou-se uma velocidade de extensão de $\mathrm{v}=3 \mathrm{~cm} / \mathrm{h}$, que corresponde $\mathrm{a} \mathrm{v}=15 \mathrm{~mm} / \mathrm{ano}$, uma vez que estudos de movimentação de placas realizados na área de estudo indicaram uma velocidade entre 10 e $25 \mathrm{~mm} / \mathrm{ano}$ (Heine et al., 2013; Quirk et al., 2013; Brune et al., 2014).

\section{Os modelos experimentais}

Os modelos experimentais foram realizados no Laboratório de Modelagem Física de Processos Geológicos Peter Szatmari, do Centro de Pesquisas, Desenvolvimento e Inovação Leopoldo Américo Miguez de Mello (CENPES/ PETROBRAS, Rio de Janeiro). A geometria da estrutura preexistente segue simplificadamente a trama do embasamento aflorante nas imediações das bacias do Espírito Santo, Campos e Santos (Figura 3A). As quebras nas linhas marcam a região onde o prolongamento das zonas de transferência encontra o continente.
Os experimentos realizaram-se em um aparelho de deformação com dimensões internas de 37 x 41 x $07 \mathrm{~cm}$ (largura $\mathrm{x}$ comprimento $\mathrm{x}$ altura). Uma parede vertical móvel de cada lado da caixa de experimentos, puxada por um motor elétrico, produziu a bacia extensional. Para reproduzir a geometria das estruturas preexistentes, utilizaram-se duas folhas de acetato na base da caixa de experimentos presas nas paredes móveis, constituindo suas terminações descontinuidades de velocidade (DV) basais (Figura 3B). Os ângulos da DV representam de forma simplificada a variação na tendência do embasamento aflorante.

Para evitar efeitos de fricção nas bordas norte e sul dos experimentos, trabalhou-se sem as paredes laterais da caixa de experimentos. Dessa forma, perdeu-se uma pequena faixa, de aproximadamente $3 \mathrm{~cm}$ de largura, a cada lado do experimento. Essas faixas foram recortadas e eliminadas das imagens apresentadas a seguir, diminuindo-se a largura dos experimentos (Figura 3B), de $37 \mathrm{~cm}$ para $31 \mathrm{~cm}$.
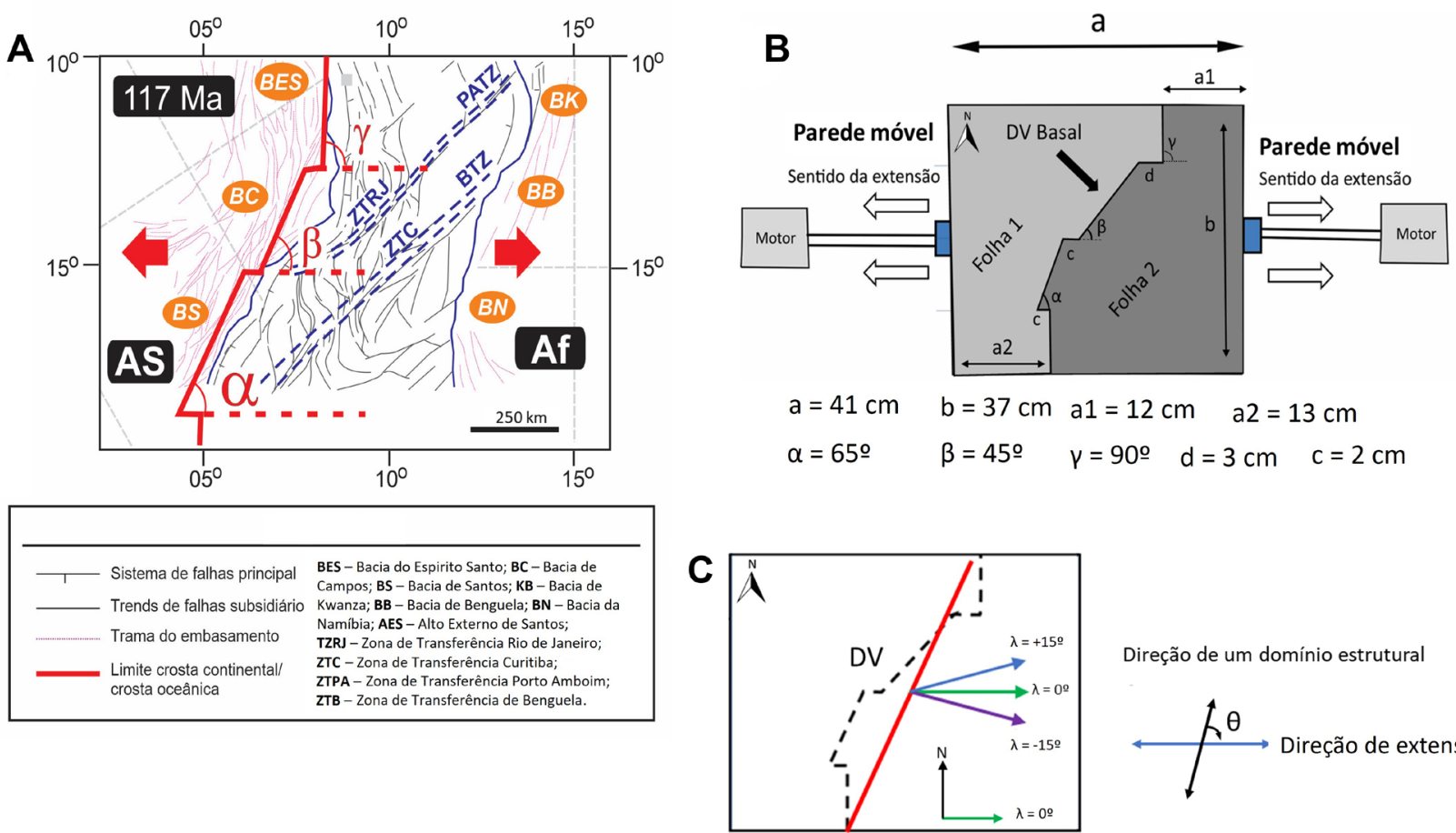

Direção de um domínio estrutural

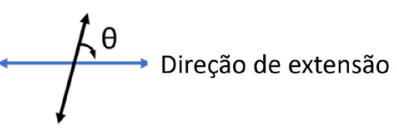

Figura 3. (A) Definição dos ângulos utilizados nas descontinuidades de velocidade basais. Notar que a geometria da descontinuidade de velocidade (linha vermelha) segue, simplificadamente, a trama do embasamento aflorante nas imediações das bacias do Espírito Santo, Campos e Santos. As quebras nas linhas marcam a região onde o prolongamento das zonas de transferência (linhas pontilhadas em azul) encontram o continente. Os ângulos $\alpha, \beta$ e $\gamma$ representam a obliquidade entre a trama do embasamento e a direção de separação (setas vermelhas) extraída da reconstrução de placas de Heine et al. (2013). (B) Figura esquemática da caixa de experimentos, em planta, com as duas folhas de acetato (Folhas 1 e 2), as descontinuidades de velocidade basais, as dimensões da caixa, os comprimentos e os ângulos dos segmentos constituintes da estrutura preexistente. (C) Direções de extensão: a seta em verde corresponde à extensão do modelo 1; em azul, à do modelo 2; em roxo, à do modelo 3; a linha vermelha representa a direção média da descontinuidade de velocidade (NNE). Para maior simplificação, representou-se, nesta figura e em todas as seguintes, apenas uma única descontinuidade de velocidade basal. O ângulo de obliquidade $(\theta)$ constitui o ângulo entre a direção de extensão e um dos quatro segmentos das DV basais. 
Com o objetivo de facilitar a descrição de metodologia e resultados dos modelos, definiu-se uma linha de direção média das DV, uma linha que conecta as extremidades sul e norte das bordas das folhas de acetato (Figura 3C). Como o aparelho de deformação é fixo, foi necessário realizar a rotação das folhas de acetado no interior da caixa de experimentos. Esse ângulo de rotação foi denominado ângulo $\mu$ (Figura 3C). O ângulo $\theta$ representa o ângulo de obliquidade entre a direção de extensão e cada um dos domínios das duas DV basais. Às vezes, menciona-se o ângulo entre a extensão e a linha de direção média das DV basais, sendo este denominado de $\theta^{\prime}$.

Realizaram-se três experimentos entre os quais se modificaram as direções da abertura, um simulando a direção $\mathrm{N} 90 \mathrm{E}\left(\mu=0^{\circ}\right.$, modelo 1), outro N75E $\left(\mu=-15^{\circ}\right.$, modelo 2$)$ e o último $\mathrm{S} 75 \mathrm{E}\left(\mu=+15^{\circ}\right.$, modelo 3$)$.

Para a área de estudo, os modelos foram simulados utilizando uma espessura de crosta continental de $40 \mathrm{~km}$ (Ros et al., 2017) (Figura 4). A crosta foi representada por uma

(i)
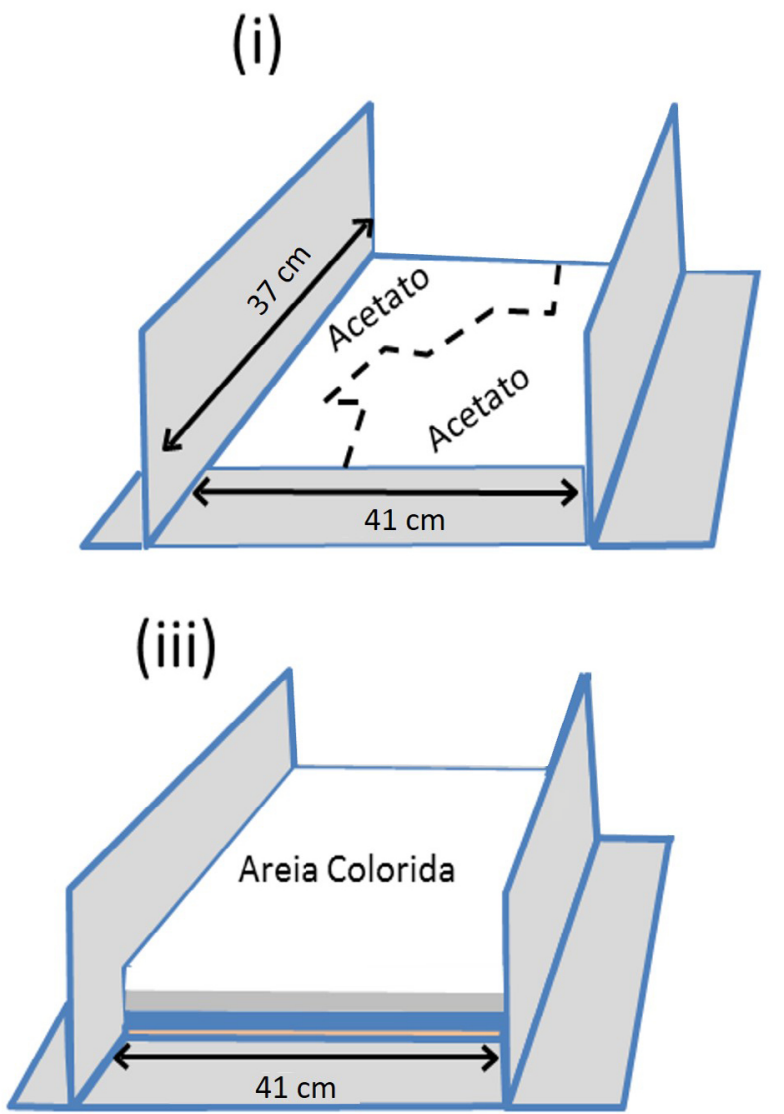

camada basal dúctil, de silicone (de $0,5 \mathrm{~cm}$ de espessura), e outra rúptil, de areia (de $3,5 \mathrm{~cm}$ ), simulando crosta inferior e superior respectivamente. A areia foi depositada em finas camadas de diferentes cores que permitiram reconhecer a deformação nas seções verticais. Após a deposição do material analógico, realizou-se uma extensão em ambos os lados da caixa de experimentos, de $3 \mathrm{~cm}$, para a geração do rifte.

Ao fim, os experimentos foram umidificados com água, o que possibilitou a obtenção de cortes no modelo, efetuados paralelos ao transporte tectônico, em intervalos regulares de aproximadamente $2 \mathrm{~cm}$. Todos os cortes foram fotografados e as imagens processadas e georreferenciadas com o software SKUA-GOCAD da Paradigm ${ }^{\mathrm{TM}}$, o qual permitiu a construção de um modelo 3D dos experimentos. Após esse processo, realizou-se a interpretação de horizontes e falhas de cada seção e gerou-se um modelo tridimensional, com falhas e horizonte do topo do embasamento. Neste, foi possível calcular as propriedades das falhas, como direção, mergulho e comprimento.

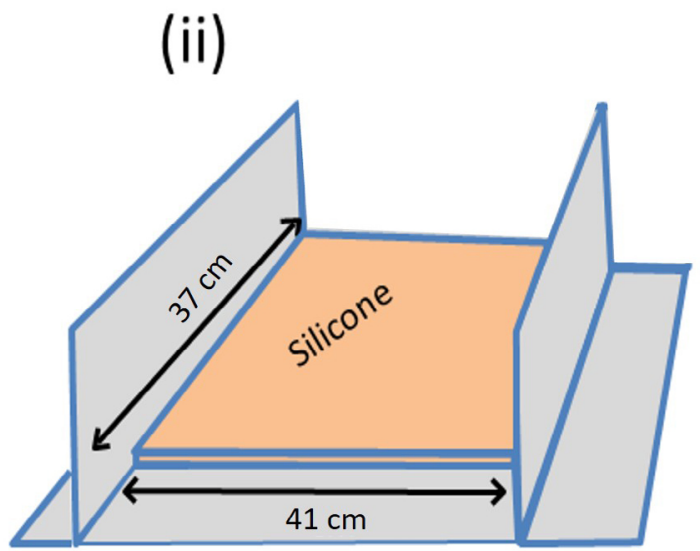

Figura 4. Configurações esquemáticas, em 3D, dos modelos: antes da deformação e da montagem do experimento, com as duas folhas de acetato na base (na posição do modelo 1); com a camada de silicone depositada sobre as folhas de acetato, representando a crosta inferior; com as camadas de areia seca, colorida, que foram peneiradas sobre o silicone, reproduzindo a crosta superior; e após a deformação final, mostrando uma estruturação de grábens e horsts. 
Para o estudo das bacias por meio do PIV, os experimentos foram repetidos sem a deposição da sequência sin-rifte, analisando apenas a estrutura do embasamento. A técnica PIV, que se baseia na correlação de imagens digitais obtidas por um conjunto de câmeras fotográficas (Figura $5 \mathrm{~A}$ ), foi usada durante todo o processo de abertura da bacia, para a análise das estruturas em planta. Imagens estereoscópicas, sequenciais, produziram campos de deslocamentos pela translação de grãos de areia por meio de um programa de computador. O processamento das imagens foi feito utilizando-se o software DaVis8 da companhia de LaVision, que, entre outros, gera mapas coloridos da magnitude de deformação (Figura 5B).

\section{RESULTADOS}

Em todos os modelos, a deformação progressiva é apresentada por três fotografias, em planta. Além disso, serão mostrados o mapa estrutural do topo do embasamento que ilustra a deformação final e seções verticais cortadas nos modelos de areia. Ao fim, será apresentada uma imagem PIV da deformação final, em planta, de cada experimento e serão discutidos os dados obtidos pelo processamento das imagens dos vários incrementos deformacionais.

A análise das fotografias do modelo $1\left(\mu=0^{\circ}\right.$, extensão E-W) (Figura 6) mostra que a extensão gerou, primeiramente, após $1 \mathrm{~cm}(2,4 \%)$ de abertura, nos domínios sul, centro-sul e entrando no domínio centro-norte, duas falhas proeminentes, curvas, com mergulhos opostos (falhas FA e FB) (Figuras 6A e 6B). Essas estruturas, que, inicialmente, constituíram as falhas de borda da sub-bacia sul do rifte (também denominada de sub-bacia 1), formaram-se sobre as DV basais. A oeste dessas falhas, apareceram os traços de duas fraturas curtas (FX e FY), com geometria en echelon. Nos domínios norte e central-norte, observam-se quatro pequenas fraturas dispostas en echelon (as futuras falhas FC, FD, FE e FF). O avanço da deformação, para $3 \mathrm{~cm}$, causou o crescimento de comprimento e rejeito dessas fraturas, que, então, caracterizam as falhas de borda da sub-bacia norte (também denominada de sub-bacia 2). Com a deformação progressiva (Figura 6C), o comprimento das falhas mais proeminentes aumentou ligeiramente, ocorrendo a conexão entre as falhas FX e FY e formando a falha FXY (Figura 6D). Esta se estende desde o domínio sul até o centro-norte e definiu uma nova falha de borda da sub-bacia 1. A distensão final foi acomodada essencialmente pela crescente abertura das sub-bacias e pela formação de maior número de outras falhas no seu interior.

A Figura 6A revela que as DV basais não controlam totalmente a direção das falhas. Percebe-se que as falhas FA e FB se iniciaram na mesma direção que o domínio sul das DV basais, no entanto, essas continuam se estendendo no sentido norte, mudando para NNE apenas ao adentrar o domínio centro-norte. A distensão de $3 \mathrm{~cm}(7,14 \%)$ (Figura 6C) mostra que, no domínio centro-norte, as falhas FC e FD, já conectadas entre si, adquiriram geometria curva com concavidade para leste. No entanto, pequenos segmentos de fraturas, em superposição e/ou en echelon, refletem a direção das DV basais. Já, no domínio norte, as falhas assumiram novamente a direção NS. Essa estruturação permanece até o fim da deformação, de $6 \mathrm{~cm}$ (14,28\%) (Figura 6D).

No modelo $2\left(\mu=-15^{\circ}\right.$, extensão ENE-WSW) (Figura 7), diferentemente do que se observa no modelo 1 , formou-se, após a extensão de $1 \mathrm{~cm}(2,4 \%)$, apenas uma falha proeminente, a falha FB (Figura 7B). Essa falha, longa e curva, que se estende da região sul até o início do domínio centro-norte, constituirá, com a deformação progressiva, a falha de
A

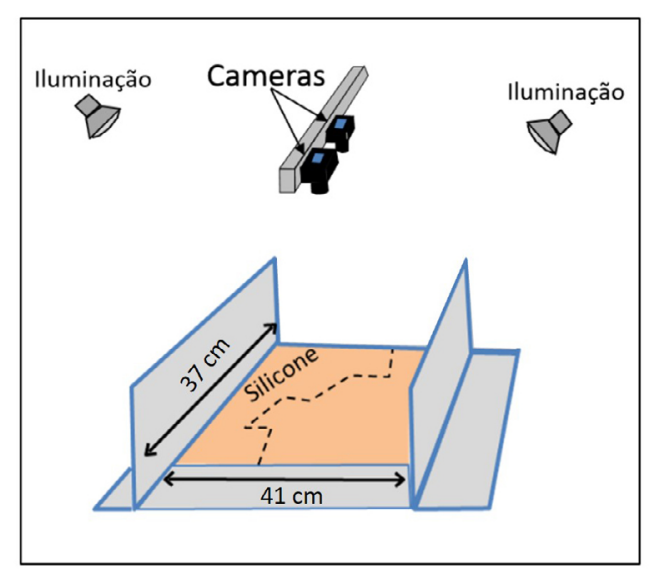

B

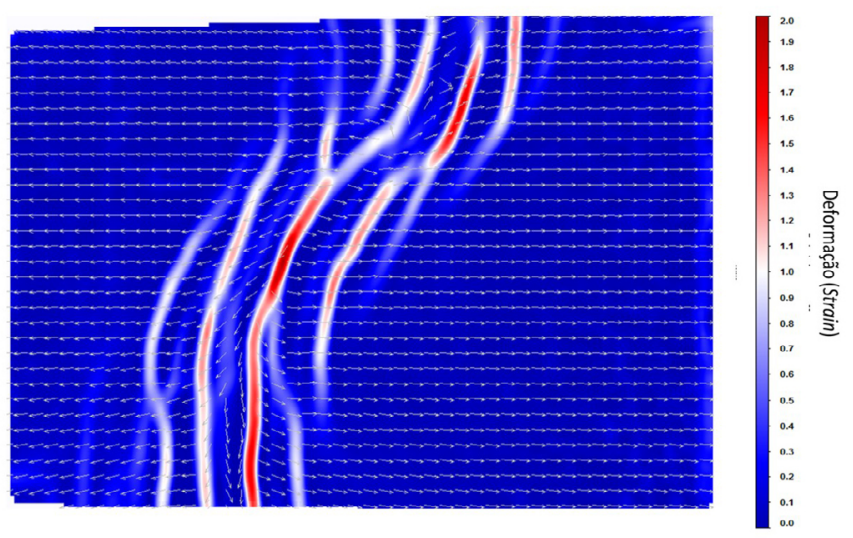

Figura 5. (A) Configuração esquemática do conjunto de câmeras do particle image velocimetry, montado acima da caixa de experimentos; (B) exemplo de um mapa da magnitude de deformação (modelo 1). 


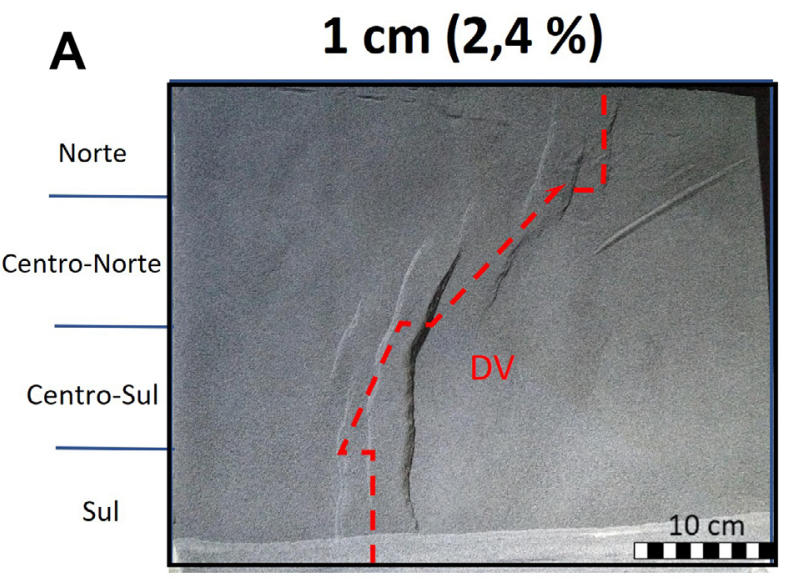

B

$1 \mathrm{~cm}(2,4 \%)$

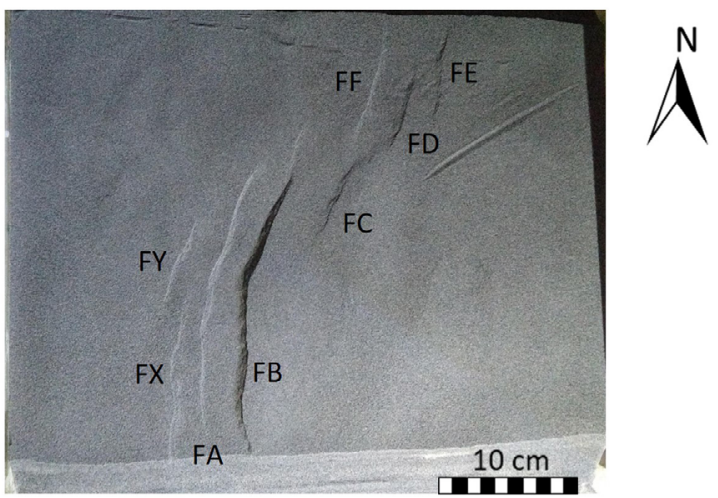

$3 \mathrm{~cm}(7,14 \%)$

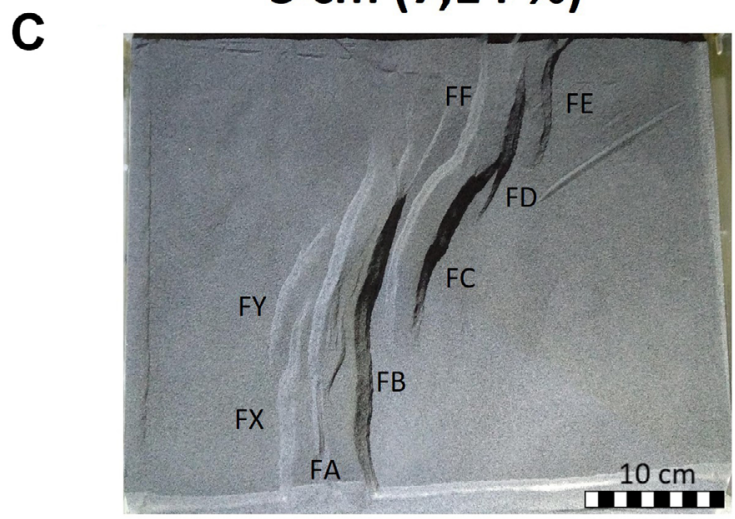

$6 \mathrm{~cm}(14,28 \%)$

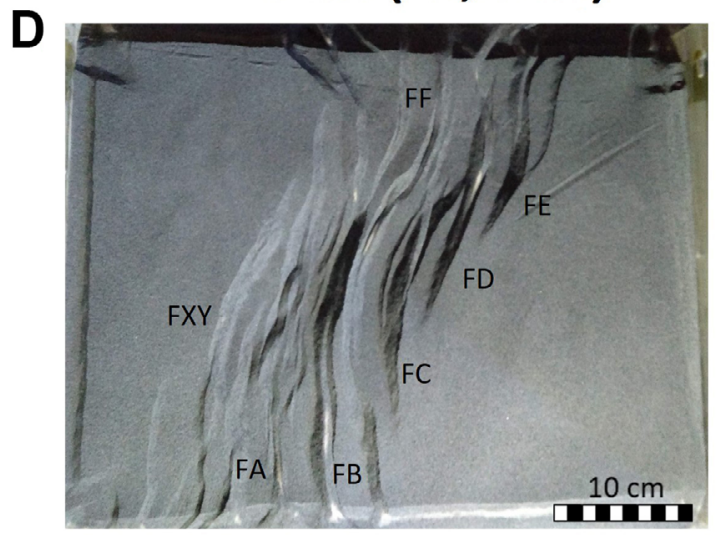

Figura 6. (A, B, C e D) Fotografias, em planta, da deformação progressiva do modelo 1; em (A) apresenta-se a posição das descontinuidades de velocidade basais (em vermelho), e assinalaram-se os domínios estruturais. As simbologias FA, FB etc. indicam falhas, conforme descrição no texto. A iluminação foi da direita para a esquerda.

borda leste da sub-bacia 1. Além dessa falha, observam-se algumas fraturas, entre as quais as mais proeminentes são duas a oeste da falha FB e outras duas nos domínios norte e centro-norte (as futuras falhas FX e FA e FE e FF, respectivamente). A deformação de $3 \mathrm{~cm}$ (Figura 7C) causou, nos domínios centro-norte e norte, a formação de quatro falhas (FC, FD, FE, FF), com geometria en echelon. Nos domínios sul e centro-sul, apareceu a falha, FY, curva, que, com a falha FX, formou as falhas de borda oeste da sub-bacia 1. Da mesma forma, como no modelo 1, a deformação final $(6 \mathrm{~cm})$ (Figura 7D) conduziu à ampliação de comprimento e ao rejeito das falhas e gerou novas falhas no interior das duas sub-bacias.

Similar ao modelo 1, apenas as falhas dos domínios sul e norte apresentam a direção dos segmentos sul e norte das DV basais (Figuras 7A e 7D), no caso, NNE. No domínio centro-sul, as falhas ainda acompanham grosseiramente o respectivo segmento das duas DV basais, e apenas no domínio centro-norte ocorre uma mudança. Neste domínio, as falhas cortam a direção do segmento subjacente.

No modelo $3\left(\mu=+15^{\circ}\right.$, extensão ESE-WNW) (Figura 8), formaram-se de forma análoga ao observado no modelo 1 , após a extensão inicial de $1 \mathrm{~cm}$ (Figura 8B), duas falhas proeminentes, FA e FB, longas e curvas. Estas se estendem do domínio sul ao norte. A oeste da falha FA, formou-se uma pequena fratura, FX, limitada ao domínio centro-sul, enquanto a leste, nos domínios sul e centro-norte, foram nucleadas duas fraturas menores, FC e FD. Com a evolução da extensão, para $3 \mathrm{~cm}$ (Figura $8 \mathrm{C}$ ), ocorreu de forma similar aos modelos 1 e 2 um aumento de rejeito e comprimento das falhas, tornando as falhas FA e FB as mais proeminentes. Na borda leste, observam-se o prolongamento da 

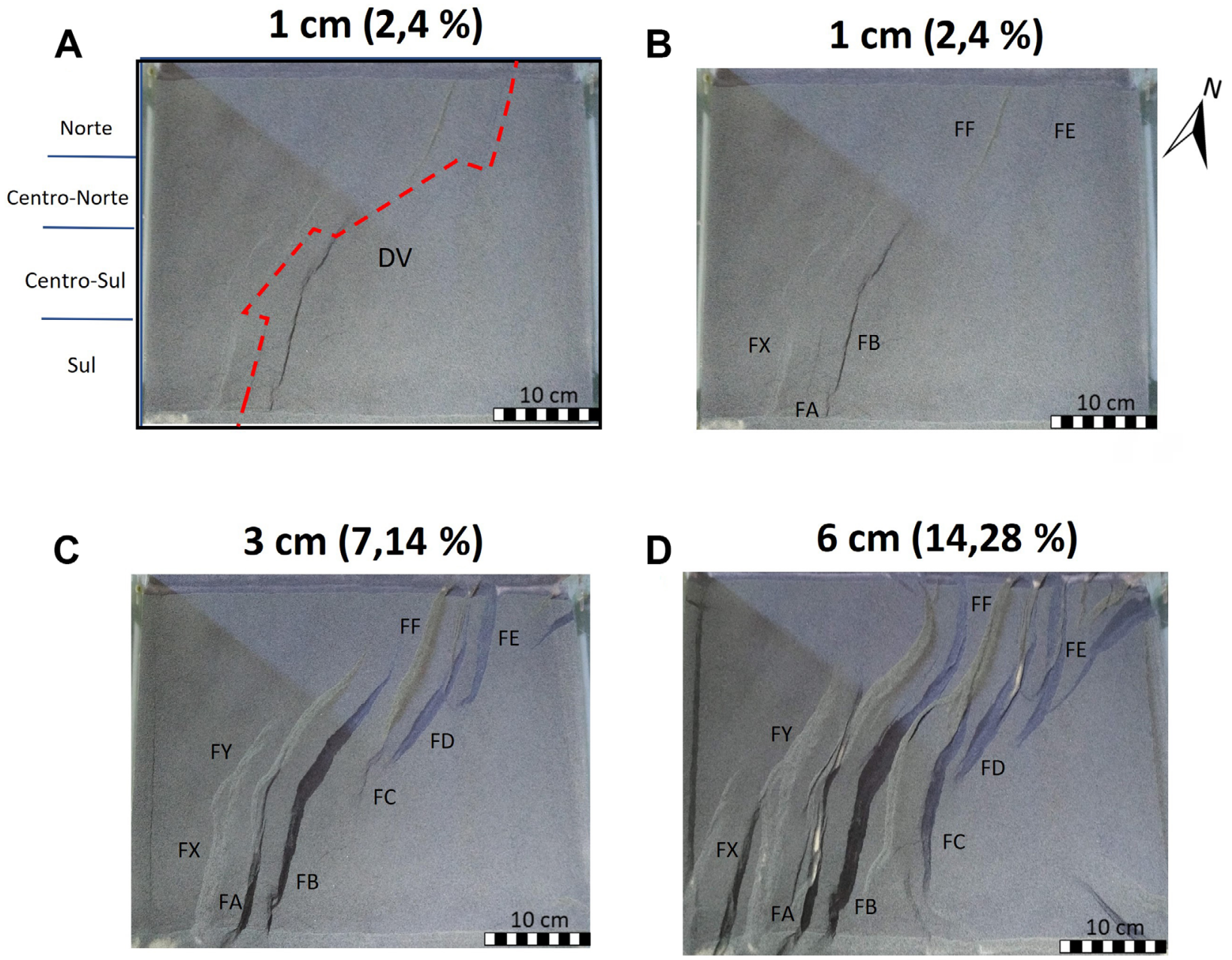

Figura 7. (A, B, C e D) Fotografias, em planta, da deformação progressiva do modelo 2; em (A) apresenta-se a posição das descontinuidades de velocidade basais (em vermelho), e assinalaram-se os domínios estruturais. As simbologias $F A$, FB etc. indicam falhas, conforme descrição no texto. A iluminação foi da direita para a esquerda.

falha FD, do domínio norte até o centro-sul, e a formação de uma pequena fratura, FE, limitada ao domínio norte. No estágio final da deformação (Figura 8D), as falhas FX e FD, nas bordas oeste e leste da sub-bacia 1, respectivamente (Figura 9C), se prolongaram por quase toda a área do experimento, enquanto a falha $\mathrm{FE}$, da região norte, se estendeu até o domínio centro-sul.

De modo geral, todo o sistema de falhas segue a tendência das DV basais. Em quase todo o experimento, as falhas possuem direção próxima a N-S, com uma pequena inflexão no domínio centro-norte, para NNE, e voltando à direção N-S novamente, no domínio norte.

Os mapas estruturais do topo do embasamento e suas respectivas seções (Figura 9) permitiram o detalhamento das feições estruturais já descritas e uma análise 3D dos modelos. É notável observar que em todos os modelos a geometria da maioria das falhas é caracterizada, em planta, por terminações finas e curvas. Comumente, essas terminações se sobrepõem formando rampas de revezamento (Figuras 9A, 9C e 9E) (tais como definidas por Larsen, 1988) ou zonas de acomodação (Faulds e Varga, 1998) (Figuras 9A e 9C).

De destaque, nos modelos 1 e 2, é um alto estrutural (AE) (Figuras 9A, 9C e 9E), que, em ambos os modelos, estende-se de sul a norte, com largura e posição ligeiramente variadas, e que separa as duas sub-bacias (Sb1 e Sb2). Trata-se de um horst, bem evidenciado nas seções 2 a 5 (Figuras 9B e 9D), nas quais esse é delimitado pelas falhas FB e FZ. Na seção 4 dos dois modelos, o AE aparece ligeiramente basculado possivelmente pelo fato de essa 

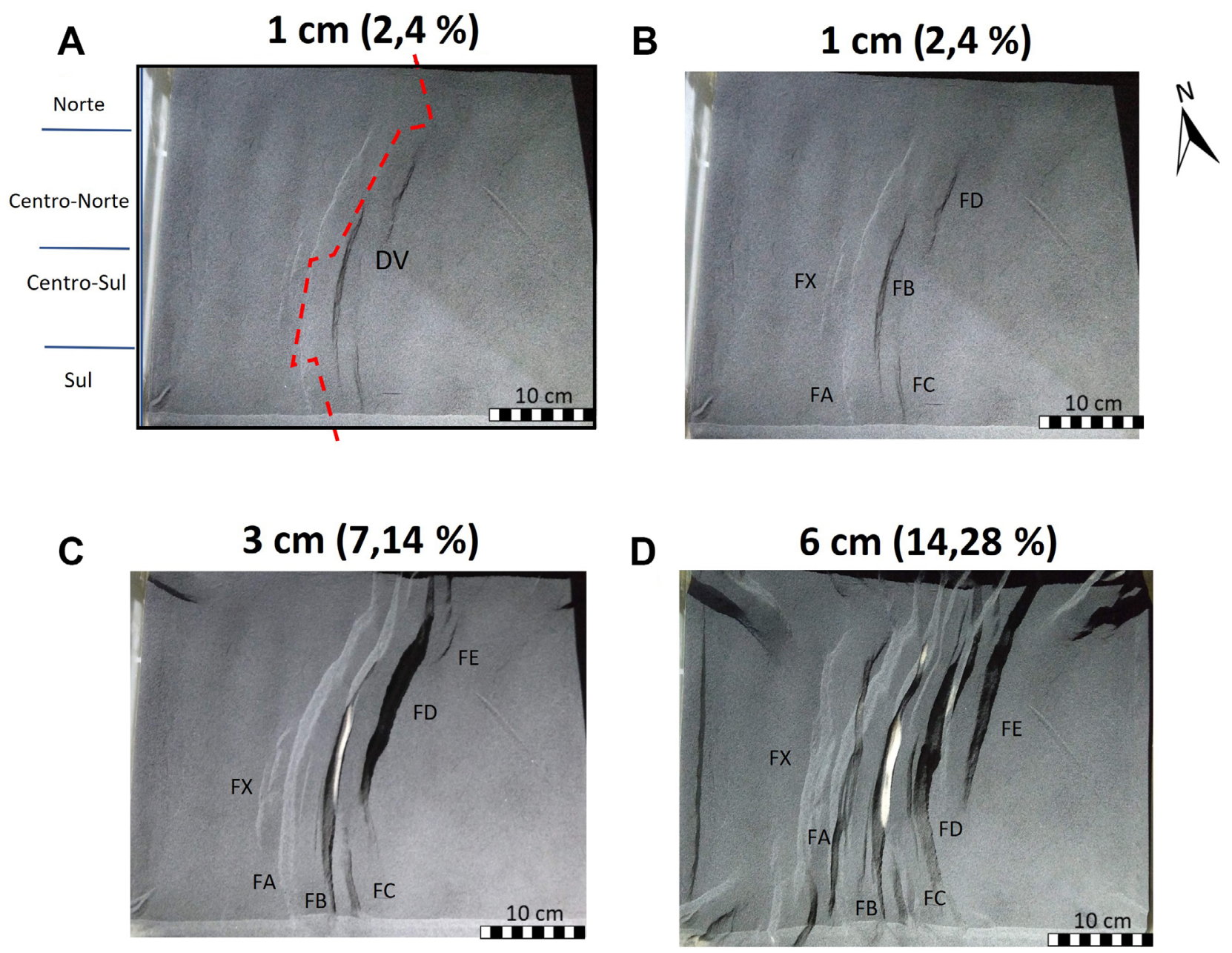

Figura 8. (A, B, C e D) Fotografias, em planta, da deformação progressiva do modelo 3; em (A) apresenta-se a posição das descontinuidades de velocidade basais, em vermelho, e assinalaram-se os domínios estruturais. As simbologias FA, FB etc. indicam falhas, conforme descrição no texto. A iluminação é da direita para a esquerda.

região constituir uma zona de acomodação. Na seção 1, do domínio sul, o horst ainda pode ser reconhecido no modelo 1 , mas desapareceu por completo no modelo 2. Além dessas estruturas, distinguem-se em todos os modelos altos e baixos secundários que se formaram em função da grande variação no número e no rejeito das falhas intra-rifte. No modelo 3, não se formou um $\mathrm{AE}$ equivalente, e, em planta, observa-se o rifte mais estreito sem desenvolvimento de sub-bacias ou zonas de acomodação.

Nas imagens do PIV (Figura 10), é interessante notar que as falhas do modelo 3 apresentam a maior deformação, isto é, o rejeito mais acentuado. A alta deformação manifesta-se nas falhas FB e FD (Figura 10C), que revelam uma deformação homogênea ao longo de toda a sua extensão. Nos outros modelos, algumas falhas também mostram magnitude de deformação relativamente alta. É o caso da falha FB, no modelo 1, assim como das falhas FD, FC e FF, dos domínios centro-norte e norte. Nessas três últimas falhas, ao contrário da falha $\mathrm{FB}$, a magnitude é maior no centro e decresce no sentido das extremidades sul e norte. O processo indica a diminuição da propagaação da deformação no sentido das extremidades das falhas, o que sugere decréscimo de rejeito nessas porções. A falha FB, do modelo 2 , que na fotografia da deformação final (Figura 7D) e no mapa estrutural (Figura 9C) foi interpretada como uma falha única, estendendo-se do domínio sul até o centro-norte, mostra na imagem PIV uma segmentação. $O$ fato sugere tratar-se, na realidade, de duas falhas. Finalmente, a falha FE, do domínio norte, exibe alta magnitude de deformação e distribuição homogênea, diferentemente das falhas FD, FC, FF, FA e FX. 

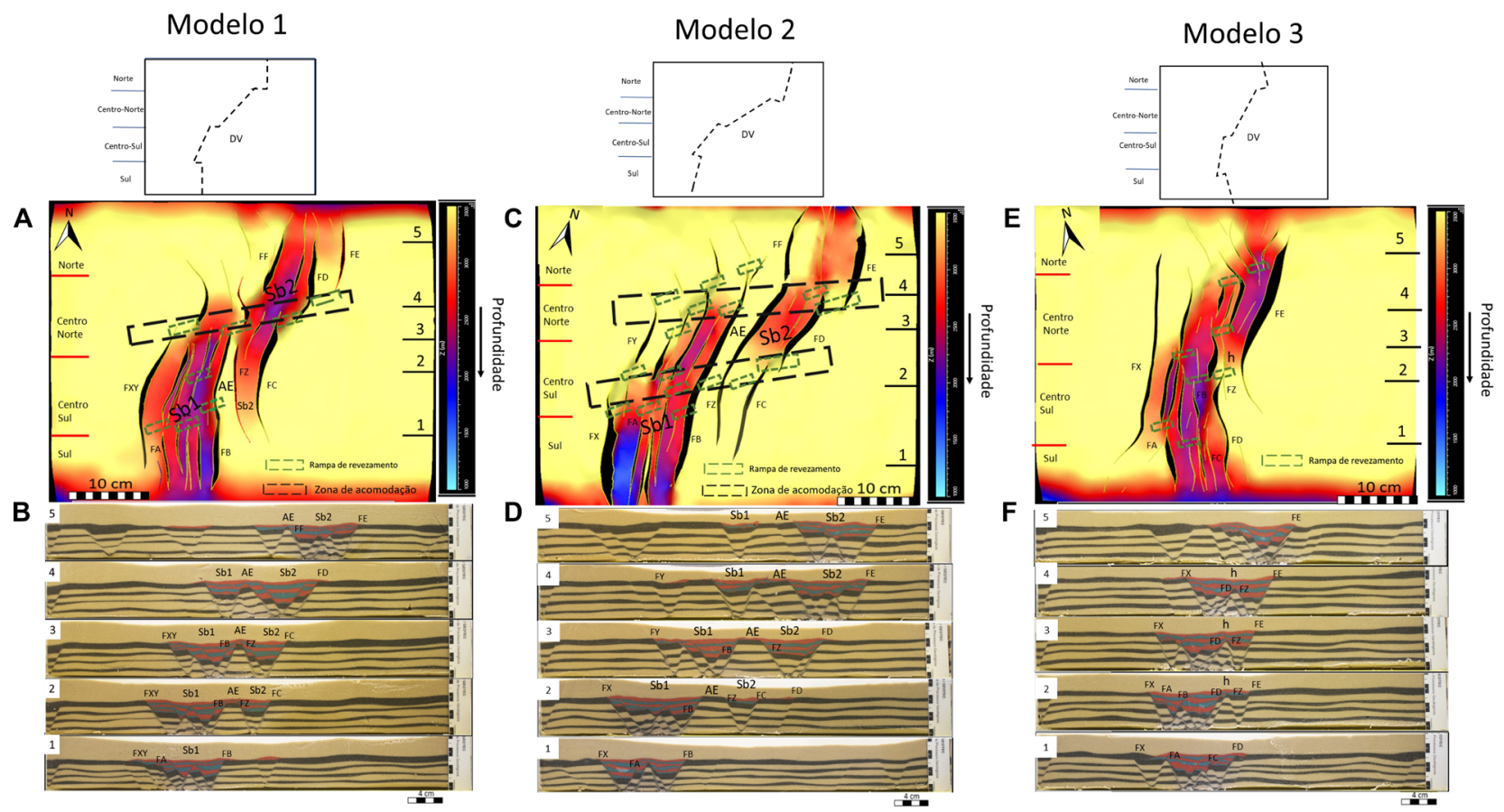

Figura 9. (A, C e E) Mapas estruturais do topo do embasamento dos modelos 1, 2 e 3, respectivamente. Cores quentes (vermelhas e amarelas) refletem os altos estruturais. O background em amarelo significa regiões onde não houve deformação, e as extremidades sul e norte do modelo (vermelha e azul) representam efeitos de borda da interpretação do horizonte do topo do embasamento nas seções. (B, D e F) Seções através dos modelos após a extensão final. As cores preta e amarela representam o embasamento do modelo, e as camadas azuis e vermelhas representam a sequência sin-cinemática. As abreviaturas $\mathrm{Sb} 1$ e $\mathrm{Sb} 2$ indicam as sub-bacias 1 e 2; AE representa o alto estrutural principal; a localização das seções está indicada nos mapas A, C e E, respectivamente.

\section{DISCUSSÃO}

\section{A comparação entre os modelos experimentais}

A análise visual da deformação final (de $14,28 \%=6 \mathrm{~cm}$, de extensão) dos três experimentos, em planta (Figuras 6D, $7 \mathrm{D}$ e $8 \mathrm{D}$ ), mostra que nenhum modelo replica fielmente os diversos domínios das DV basais. Esse fato pode estar relacionado com a presença da camada basal de silicone, que nos experimentos representa a crosta inferior, dúctil. O silicone sob a areia causa forte distribuição da deformação, uma vez que age como um amortecedor que desacopla a camada rúptil da base da caixa de experimentos (conforme, por exemplo, Pinto et al., 2010; Zwaan et al., 2018; Del Ventisette et al., 2019). Ao contrário, em experimentos montados apenas com areia, rúptil, a deformação é mais localizada.

A deformação inicial dos modelos (de 1 e $3 \mathrm{~cm}$ ) mostra, no entanto, a formação de fraturas paralelas a alguns domínios das duas DV basais (Figuras 6B, 7B e 8B). Com a evolução da deformação, as fraturas mudam de orientação na transição entre domínios (Figuras $6 \mathrm{C}, 7 \mathrm{C}$ e $8 \mathrm{C}$ ). Nos modelos $1 \mathrm{e} 2$, só não ocorre uma mudança de orientação das fraturas entre os domínios sul e centro-sul, possivelmente, pelo fato de possuírem ângulos de obliquidade próximos da ortogonal $\left(\theta\right.$ entre 65 e $\left.90^{\circ}\right)$. Nas transições dos domínios centro-sul para centro-norte e centro-norte para o norte, a mudança de direção causou pequenas e suaves curvaturas nos traçados das falhas. Sugere-se, que, nesse caso, ângulos de obliquidade $(\theta)$ entre 30 e $65^{\circ}$ controlem a orientação das falhas. Nenhuma mudança de direção é observada no modelo 3 ( $\theta$ entre 60 e $105^{\circ}$ ), cujo sistema de falhas caracteriza uma grande e suave curvatura desde o início da deformação.

A Figura 11 ilustra uma análise estatística dos dados encontrados nos modelos. Os estereogramas das Figuras 11D, $11 \mathrm{E}$ e $11 \mathrm{~F}$ mostram os máximos estatísticos das atitudes dos planos das falhas para cada modelo. Esses refletem os pares conjugados de falhas que, no modelo 1 , correspondem a N10E/65SE e N17E/60NW, no modelo 2, a N25E/63SE e N30E/60NE, e, no modelo 3, a N2E/65SE e N5E/60NW. Percebe-se que os modelos $1 \mathrm{e} 2$ formaram falhas oblíquos à direção da extensão enquanto no modelo 3 , as falhas foram geradas praticamente ortogonal à extensão (vide também os mapas dos traços de falhas das Figuras 11G, 11H e 11I). 

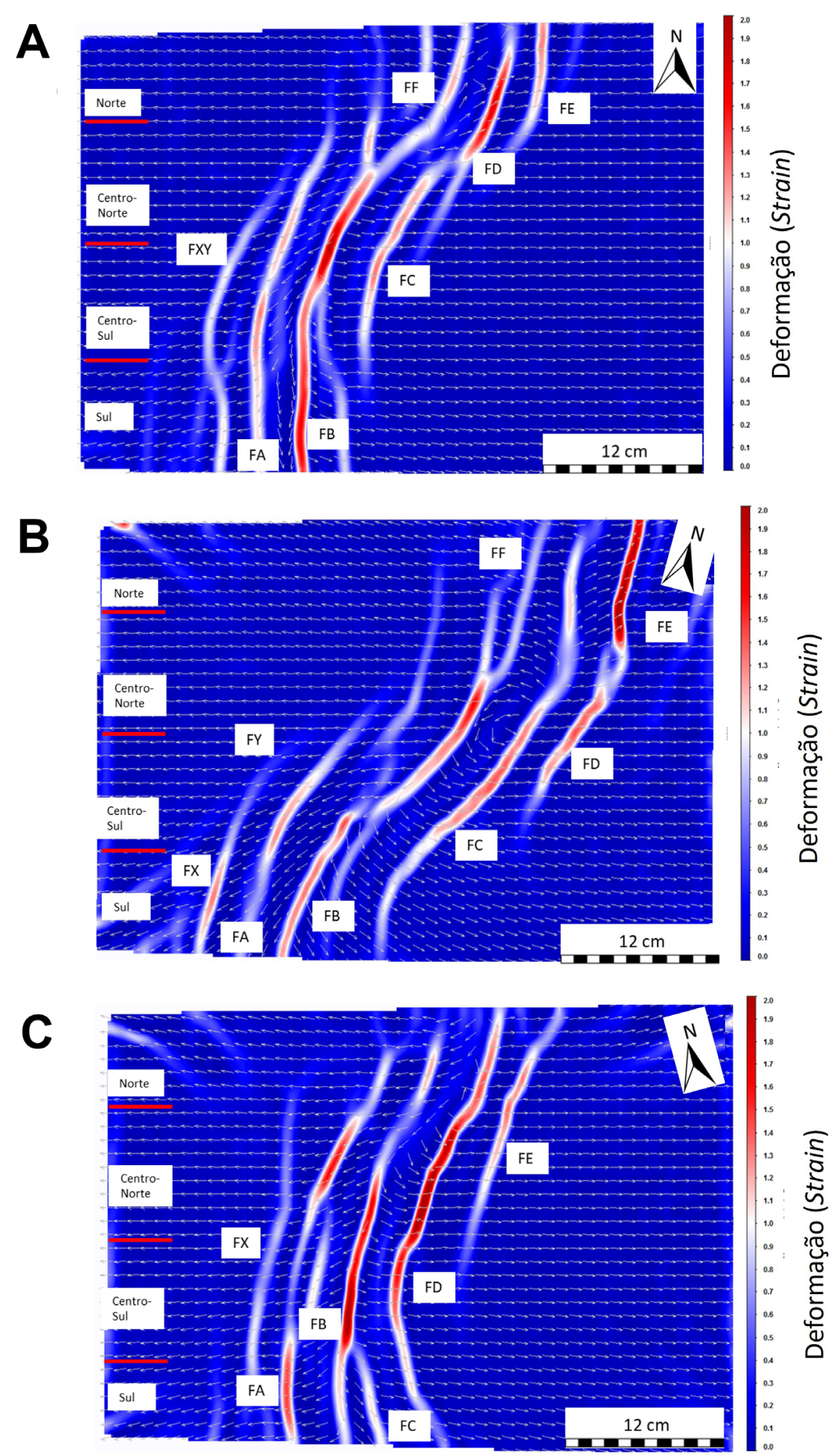

Figura 10. (A, B e C) Imagens particle image velocimetry refletem a deformação do último estágio de extensão $(6 \mathrm{~cm})$ dos modelos 1,2 e 3 , respectivamente. A cor vermelha representa maior intensidade da deformação, conforme escala na lateral. As setas indicam a direção onde os grãos de areia foram movimentados durante o experimento. 

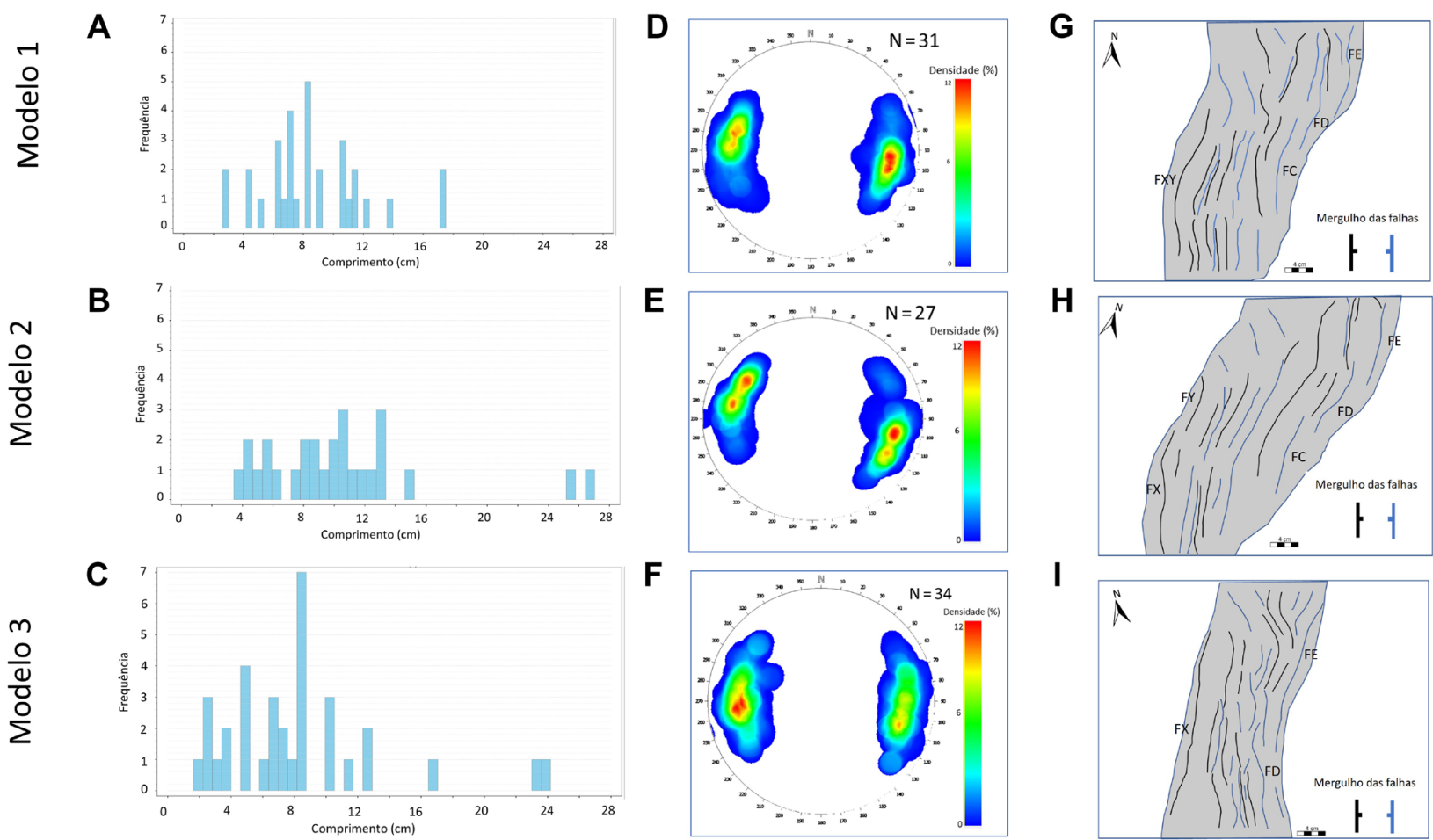

Figura 11. Representação das falhas mapeadas nos três modelos desenvolvidos. (A, B e C) Histogramas dos comprimentos; (D, E e F) Estereogramas das atitudes. N representa o número de falhas. (G, H e I) Mapas dos principais traços de falhas na superfície dos modelos. As linhas pretas representam falhas mergulhando para a direita e as linhas azuis para a esquerda. As setas duplas indicam a abertura da bacia.

A dispersão dos dados observada nos três estereogramas reflete a distribuição da deformação decorrente da presença da camada basal de silicone, mencionada anteriormente.

A análise dos histogramas que relacionam a frequência com os comprimentos dos traços das falhas dos três modelos (Figuras 11A, 11B e 11C) permitiu classificar as falhas em três grupos: curtas $(0 \mathrm{a} 8 \mathrm{~cm})$, intermediárias $(8 \mathrm{a} 16 \mathrm{~cm}) \mathrm{e}$ longas ( 16 a $28 \mathrm{~cm}$ ). Nos modelos $1 \mathrm{e} 2$, as falhas intermediárias são as mais representativas. Constituem 49\% e 64\% do total de 31 e 27 falhas, respectivamente. No modelo 3, que desenvolveu uma quantidade maior de falhas (34), destacam-se as falhas longas apesar de somarem apenas $10 \%$. Nos modelos 1 e 2, essas falhas reúnem apenas $6 \%$ do seu total. As falhas curtas possuem uma dispersão maior: os modelos 1 e 2, com $45 \%$ e $30 \%$ das falhas, respectivamente, e o modelo 3, com $52 \%$.

Nos modelos 1 e 2, a deformação final (Figuras 6D e 7D) mostra que o grupo de falhas curtas replica a direção das DV basais nos domínios sul e norte. Já os grupos de falhas longas e intermediárias ocorrem em toda a região central desses modelos (vide mapa de traços das Figuras 11G, $11 \mathrm{H}$ e 11I) cortando os segmentos da estrutura sotoposta e formando pequenas curvas nos segmentos $\mathrm{E}-\mathrm{W}$ das DV basais. O modelo 3 exibe as mesmas feições, porém de forma mais sutil.

Para a formação do AE, descrito nos modelos 1 e 2 (Figuras 9B e 9D, seções 2 a 5), que divide a bacia em duas sub-bacias ( $\mathrm{Sb} 1$ e Sb2), sugere-se uma relação com a direção da extensão e a geometria das DV basais. Os mapas das DV basais (Figura 12, coluna da esquerda) indicam, nesses modelos, que o segmento do domínio centro-norte, mais longo, une trechos das DV basais de direções muito desiguais, os quais teriam, com a abertura do rifte, induzido a formação do AE. O modelo 3 (Figura 12C) não possui diferenças significativas de direção entre os domínios das DV basais, o que resultou em um modelo mais homogêneo. Daí derivou a formação de uma bacia contínua (Figura 12, coluna da direita).

As imagens PIV permitem sugerir a direção do deslocamento dos principais blocos de falhas por meio de pequenas setas que representam os vetores do movimento das partículas granulares (Figura 10). No interior do rifte, no modelo 1, a oeste da porção sul da falha $\mathrm{FB}$, as setas apontam para sul, e, mais a norte, para SW. No primeiro caso, os vetores do movimento refletem um basculamento do bloco de falha para sul, e, no segundo, uma abertura oblíqua. Na região leste 

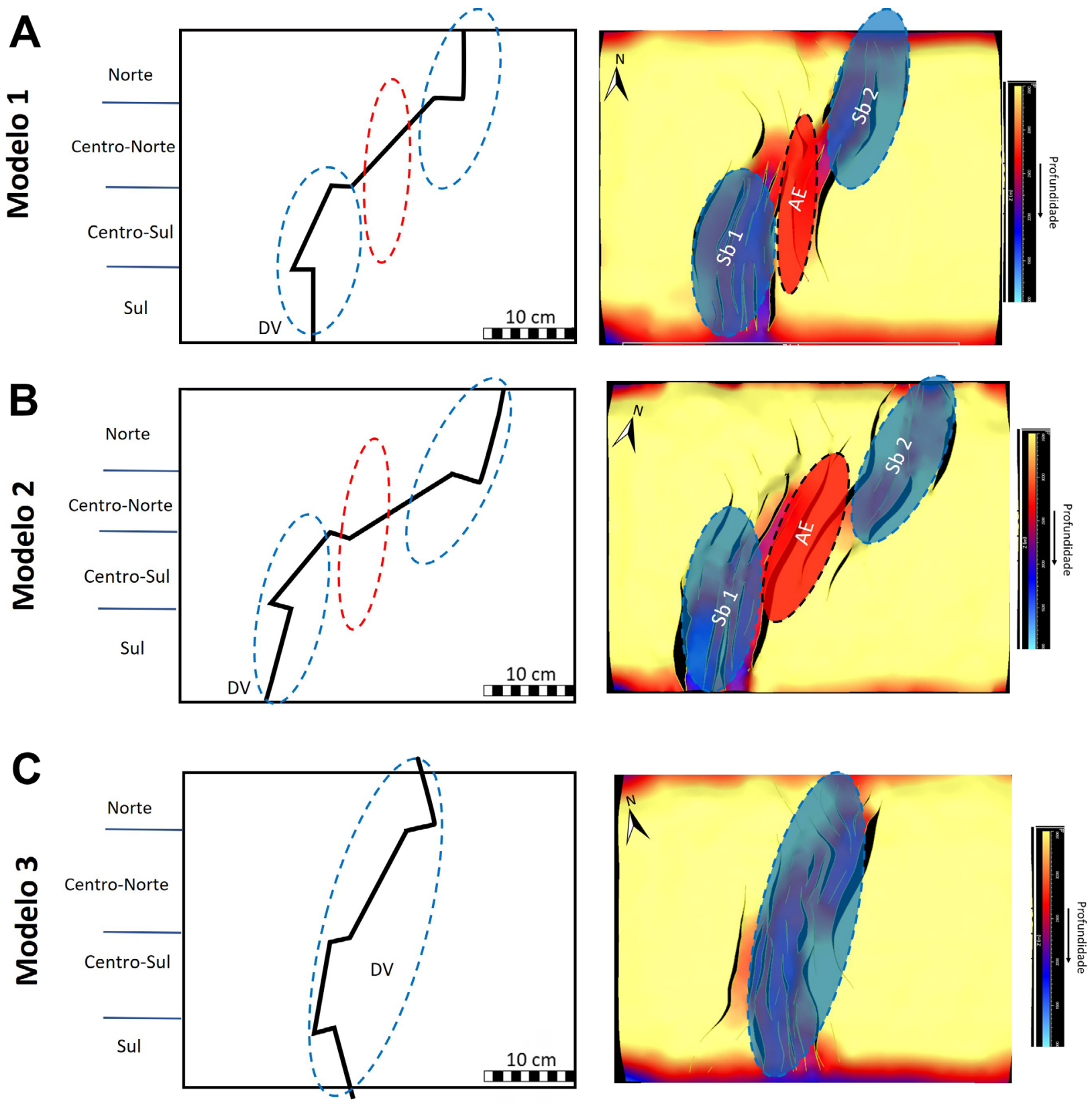

Figura 12. Representação das descontinuidades de velocidade basais (coluna da esquerda) dos três modelos e dos mapas estruturais do topo do embasamento (coluna da direita); na coluna da esquerda, as elipses azuis hachuradas mostram os segmentos das descontinuidades de velocidade basais cujas direções condicionaram a formação do alto estrutural; observar que, no modelo 3, a direção regional das descontinuidades de velocidade é relativamente homogênea e nenhum alto estrutural se formou; na coluna da direita, são indicadas as sub-bacias (Sb) e a bacia contínua por elipses azuis e os altos estruturais (AE) por elipses vermelhas.

da falha FB, na transição dos domínios central-norte e norte, as setas que mostravam para SE mudam e evidenciam uma rotação anti-horária na direção das partículas. Esse processo possivelmente ilustra a interação entre falhas e que conduziu à formação de uma rampa de revezamento. $\mathrm{O}$ modelo
2 revela, nos domínios sul até centro-norte, setas formando um ângulo agudo com o traço das falhas, o que sugere movimento oblíquo dos blocos. No domínio norte, a direção das setas é aproximadamente E-W, indicando um movimento ortogonal à direção das falhas. Finalmente, nas transições dos 
domínios sul para o centro-sul e centro-norte para o norte, observa-se novamente uma rotação anti-horária nos vetores do movimento das partículas granulares. Essa rotação é também interpretada como resultante da formação de rampas de revezamento. Diferentemente dos modelos 1 e 2, a extensão no modelo 3, cujo sistema de falhas, em planta, é quase reto e tem direção aproximadamente $\mathrm{N}-\mathrm{S}$, causou movimentação das partículas, em geral, E-W. O fato sugere uma extensão praticamente ortogonal, em todo o experimento. No entanto, na transição entre os segmentos de falhas ocorrem pequenos desvios na direção das setas, indicando o processo de formação de rampas de revezamento.

As discussões anteriores evidenciam que os modelos 1 e 2 se assemelham entre si e se diferenciam do modelo 3 . Como já apontado, esse fato deve estar relacionado com os ângulos $\theta$ ' (entre a direção da extensão e a linha de "direção média" das DV basais) e $\theta$ (entre a direção da extensão e os diversos segmentos das DV basais), uma vez que os modelos 1 e 2 apresentam $\theta^{\prime}<90^{\circ}$, enquanto o modelo 3 revela $\theta^{\prime} \approx 90^{\circ}$.

\section{Comparação com trabalhos anteriores}

Os modelos aqui desenvolvidos apresentam similaridades com interpretações de modelos anteriores nos quais a formação, evolução e segmentação dos riftes são fortemente influenciadas pela presença de estruturas preexistentes e pelo ângulo de obliquidade $(\theta)$ de cada experimento (McClay et al., 2002; Schlische et al., 2002; Corti et al., 2007; Agostini et al., 2009; Autin et al., 2013; Zwaan et al., 2016).

McClay et al. (2002), por exemplo, analisaram sistemas de riftes ortogonais, oblíquos e com deslocamentos laterais em modelos de areia. Os riftes foram simulados em caixas de experimentos decimétricos montados sobre duas placas de alumínio presas entre si por uma folha de borracha, central. Nos experimentos de extensão ortogonal, os autores identificaram falhas longas e retilíneas, a presença de um pequeno número de rampas de revezamento e nenhuma zona de acomodação. Essas feições se assemelham às características do presente modelo 3.

Já, nos modelos de rifteamento oblíquo, com e sem deslocamento lateral, os autores observaram falhas segmentadas e com geometria en echelon nas bordas das bacias. Além disso, reconheceram grande número de rampas de revezamento e zonas de acomodação, assim como a mudança de direção de depocentros. Características similares foram observadas nos modelos 1 e 2 .

Corti et al. (2007) simularam em experimentos físicos o ramo oeste do rifte Leste Africano com o intuito de estudar a relação entre as estruturas preexistentes e a arquitetura do rifte. De forma análoga aos realizados neste estudo, os autores utilizaram uma folha de acetato para gerar a extensão e empregaram, para a crosta inferior dúctil e a superior rúptil, uma mistura de areia de coríndon com silicone e areia de quartzo, respectivamente. Os dois estudos diferenciam-se de trabalhos anteriores por considerarem DV basais com geometria irregular. Corti et al. (2007) usaram uma DV curva e, em dois experimentos, um simples e outro com zonas de fraqueza preexistentes, replicaram a curvatura preexistente, em escala regional. Os autores sugerem que o fato implica que sob um campo de extensão constante ocorre extensão ortogonal, em algumas regiões, e oblíqua, em outras. A variação na direção da extensão gerou efeitos tais como mudanças na assimetria do rifte, segmentação da bacia e variações na arquitetura das falhas de borda (direção, comprimento e cinemática). Entre outros, ainda concluíram que zonas de fraqueza preexistentes podem influenciar a posição de zonas de acomodação e que o magmatismo e a mudança no campo de deformação podem controlar as estruturas em escala local.

\section{A comparação entre os modelos experimentais e a Bacia de Santos}

Entre as principais estruturas intrabacinais, o Alto Externo da Bacia de Santos (AEBS) é a mais importante estrutura do embasamento (Figura 13A) (Gomes et al., 2008), sendo o alto mais proeminente e extenso do rifte da Bacia de Santos (Gomes et al., 2008), apresentando formato alongado, de direção NE-SW. Antes da quebra continental, no Aptiano, o AEBS estava localizado a aproximadamente $200 \mathrm{~km}$ tanto do Brasil quanto da África. A característica de ambiente distal associado ao relevo positivo do embasamento (Figura 13A) limitou a entrada de sedimentos siliclásticos na bacia, que teriam sido ideais para a formação de uma ampla plataforma carbonática durante o Aptiano inferior. Nos modelos 1 e 2 (Figura 13B), é possível identificar um alto estrutural (AE) delimitado por duas falhas proeminentes que condicionaram a formação dos depocentros adjacentes, situação muito semelhante àquela da seção sísmica interpretada (Figura 13A).

$\mathrm{O}$ mapa de anomalia free-air da Bacia de Santos (Figuras 13C) mostra a disposição do AEBS limitado por dois depocentros adjacentes. Essa configuração estrutural foi gerada nos modelos experimentais 1 e 2, especialmente no modelo 2, como pode ser visualizado em respectivo mapa estrutural do topo do embasamento (Figura 13D).

Segundo Fossen e Rotevatn (2016), em riftes caracterizados pela presença de um alto estrutural, a interação e a sobreposição de falhas pode causar a formação de sub-bacias de disposições distintas. A mudança de depocentros em riftes oblíquos é descrita em diversas outras bacias, por exemplo, nos riftes do Leste Africano (Corti, 2012), do Golfo da Tailândia (McClay et al., 2004) e do Mar do Norte (Zwaan et al., 2016).

O mapa do topo estrutural do embasamento da porção centro-norte da Bacia de Santos (Figura 14A) revela vários 


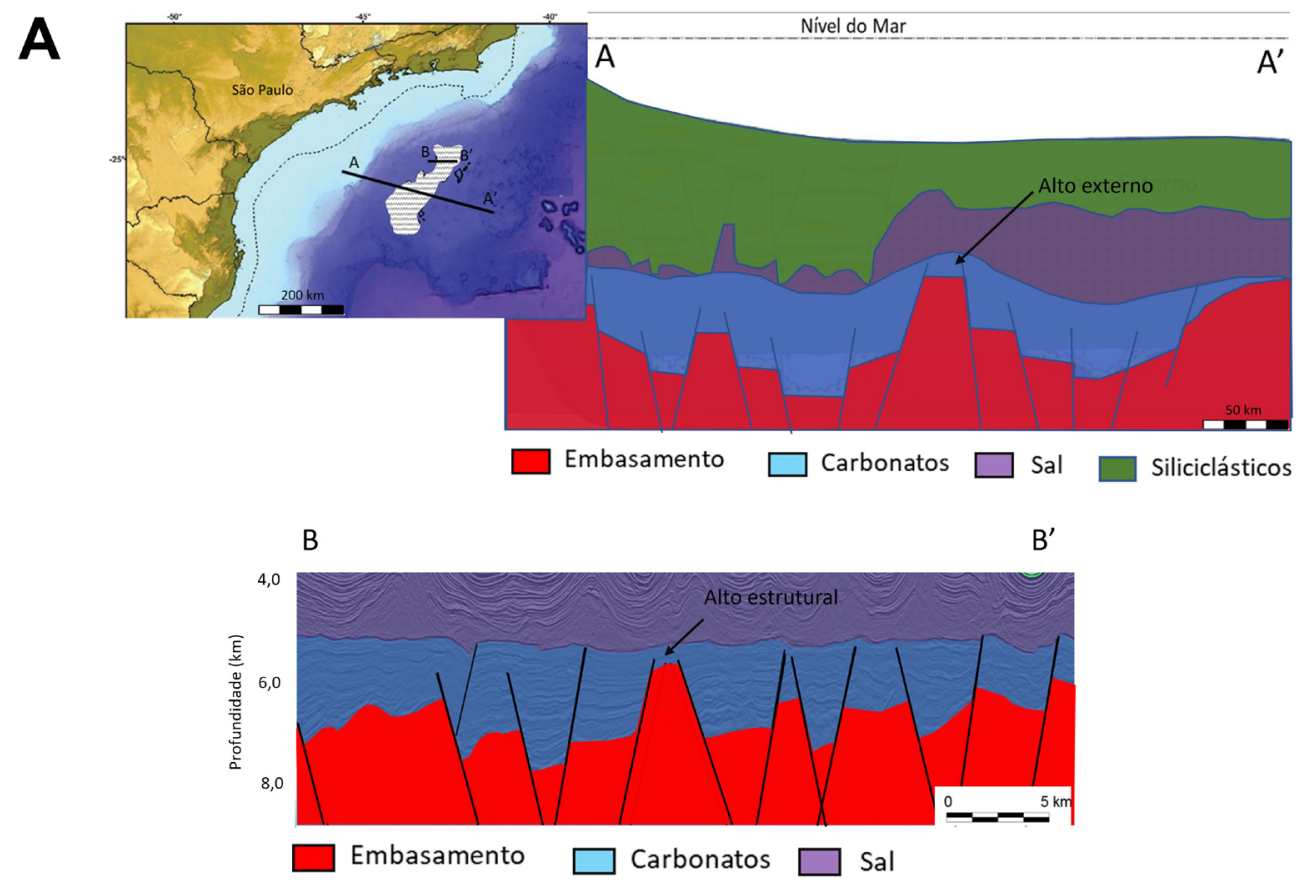

B
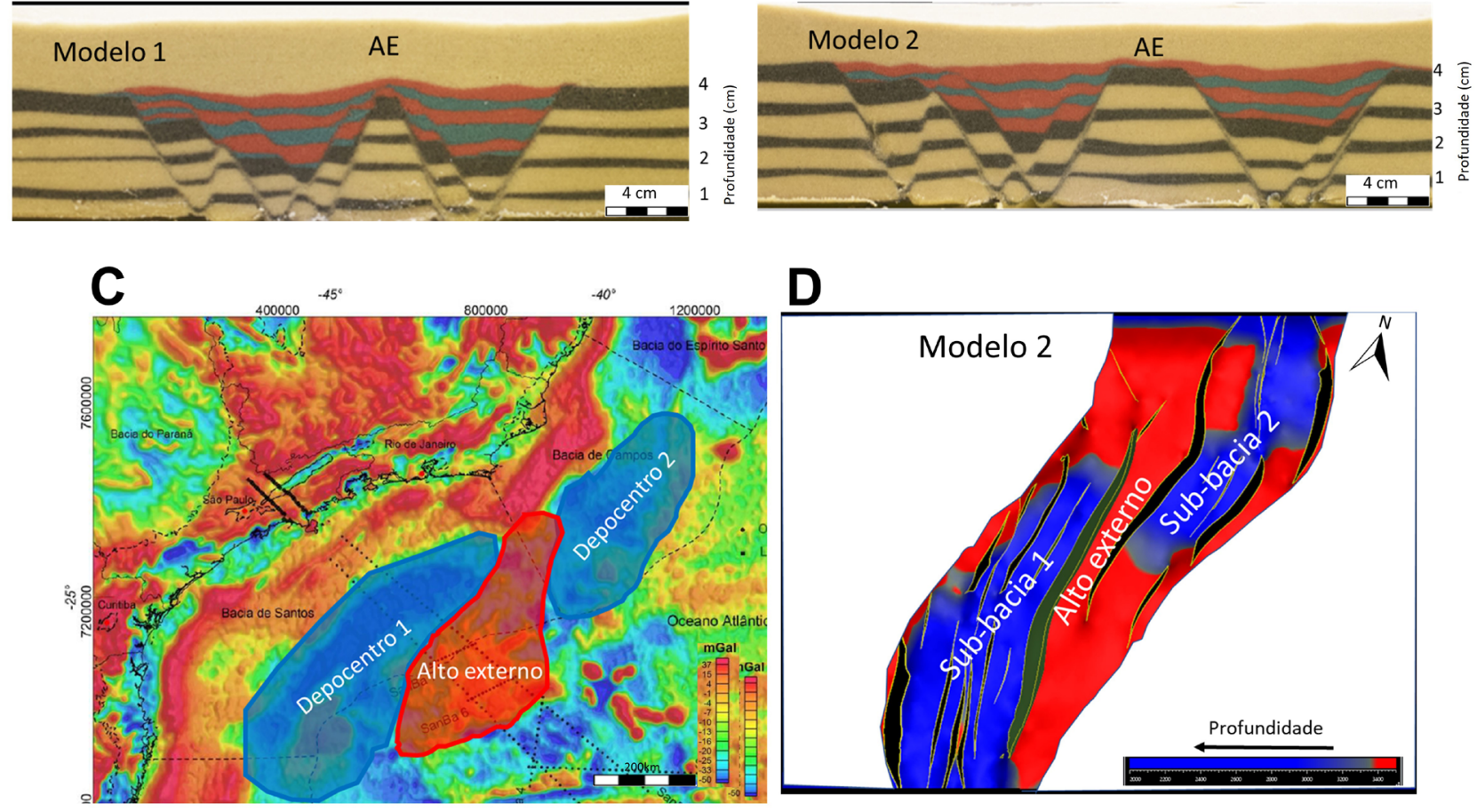

Figura 13. Imagens da Bacia de Santos e dos modelos experimentais. (A) Seções geológicas esquemáticas WNW-ESSE (AA') (modificado de Zhang et al., 2020) e E-W (BB') (Pereira, 2021) e mapa de localização; (B) as seções da região central dos modelos experimentais 1 e 2; e mapas (C) de anomalia free-air (modificado de Rigoti, 2015) e (D) estrutural do topo do embasamento do modelo 2. Ambos os mapas ilustram a disposição do alto externo com a posição escalonada dos depocentros. As cores azuis representam estruturas mais profundas e as vermelhas mais rasas. 
altos estruturais e falhas associadas que, em conjunto, compõem a feição denominada de "S" de Santos (Magnavita et al., 2010). Essa estrutura é caracterizada pela mudança de direção das falhas. As regiões sul e norte apresentam falhas NE-SW, enquanto, na parte central, a direção é NW-SE. Sugere-se que, à semelhança dos modelos 1 e 2, a mudança de direção dessas falhas foram causadas por estruturas preexistentes, no caso a Charneira do Cretáceo.

Entre os mapas estruturais do topo do embasamento dos modelos físicos, o modelo 1 revela melhor o formato em "S" do sistema de falhas normais associado a uma zona de acomodação. Considerando-se que o ângulo de extensão, $\mu=0^{\circ}$ (Figura 3) do modelo 1, corresponderia na natureza a uma extensão N90E, sugere-se que a direção de extensão desSe modelo constitua um argumento a favor da direção de abertura do rifte.

\section{CONCLUSÃO}

Os modelos físicos mostraram que a formação de um rifte é fortemente influenciada pela geometria da estrutura preexistente. Nenhum modelo reproduziu de forma exata os vários domínios da estrutura preexistente, possivelmente em função da camada de silicone basal, que representou a crosta dúctil. Dependendo da direção de extensão e consequentemente do ângulo de obliquidade $(\theta)$ (o ângulo entre a direção de extensão e cada um dos segmentos das DV basais), a transição entre os diversos domínios da estrutura preexistente causou falhas com traços curvos, em planta, ou zonas de acomodação. Não foram observados nos modelos movimentos oblíquos, sendo todas as falhas dominantemente normais. A obliquidade nesse caso foi absorvida na forma do aumento do escalonamento das falhas intrabacinais, conforme se aumenta a obliquidade entre a trama do embasamento e a direção de extensão.

Os experimentos mostraram que, na maior parte dos casos, os modelos 1 e 2 diferenciam-se do modelo 3 , uma vez que os primeiros apresentam ângulo de obliquidade $\theta^{\text {' }}$ $<90^{\circ}$ e o modelo $3, \theta^{\circ} \approx 90^{\circ}$ (o ângulo entre a direção de extensão e a linha média das DV basais). Os modelos 1 e 2 apresentaram significativas mudanças de direção dos traços das falhas, quando estas passam de um domínio da estrutura preexistente a outro (exceção para a transição entre o domínio sul e centro-sul), resultando uma geometria em "S". Nos modelos de extensão oblíqua ainda se destacou a formação de um alto estrutural que separa os modelos em duas sub-bacias, dispostas en echelon. O modelo 3, de extensão próxima à ortogonal, gerou um sistema de falhas mais estreito com maior número de falhas longas, caracterizadas pela magnitude de deformação mais alta. Esse modelo, no entanto, nucleou o menor número de rampas de revezamento, e nenhuma zona de acomodação foi observada.

Os modelos 1 e 2 foram os que apresentaram as principais semelhanças com as estruturas encontradas na Bacia de Santos. Ambos os modelos geraram um alto estrutural

\section{A}

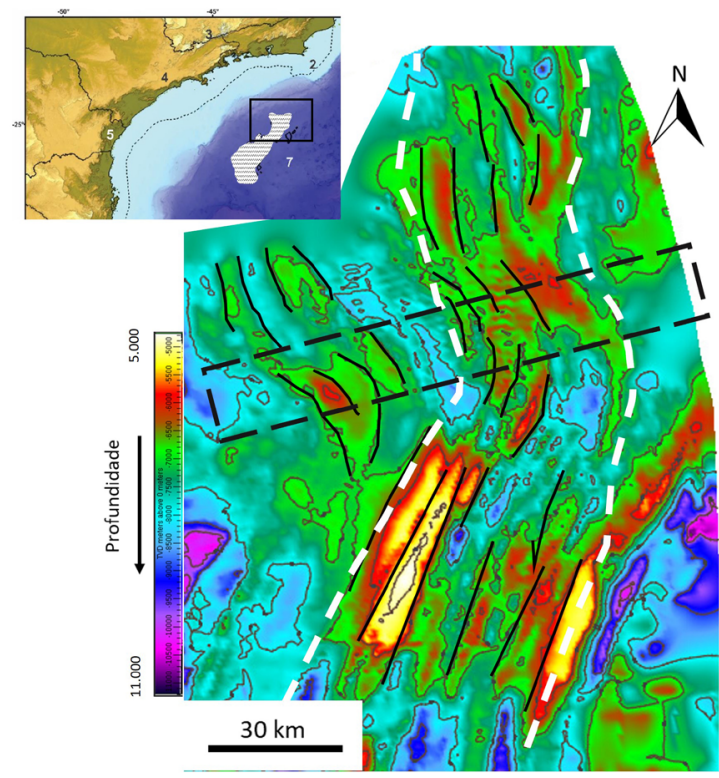

B
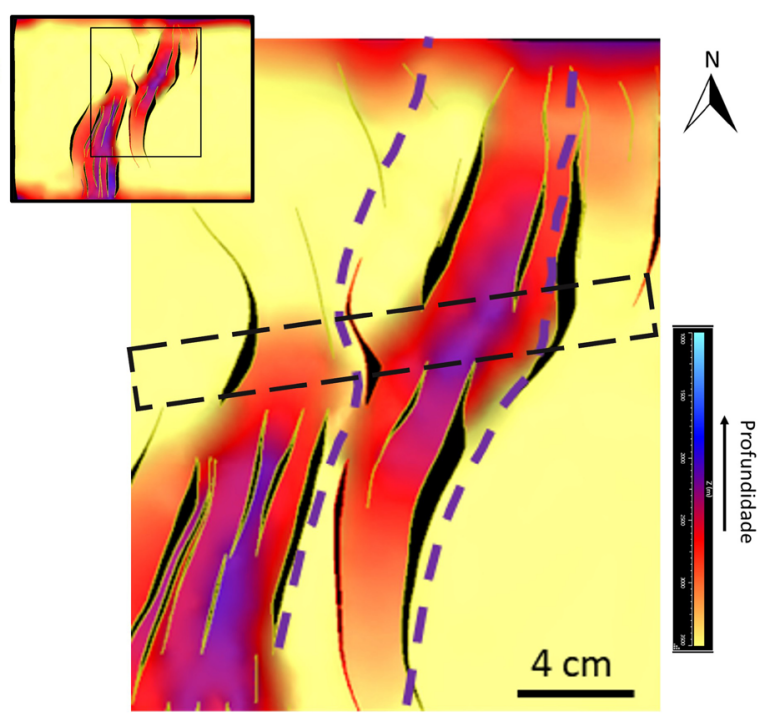

Г_ - Z Z Zona de acomodação

Figura 14. Mapas estruturais do topo do embasamento da porção centro-norte da Bacia de Santos (A) do protótipo (Pereira, 2021) e (B) do modelo 1 que ilustram a variação nas direções das falhas (linhas pretas), o sistema de falhas em "S" de Santos (linhas tracejadas) e a zona de acomodação. 
(AE) relacionável ao alto externo da bacia (AEBS) (Gomes et al., 2008). Além disso, a significativa compartimentação produziu rampas de revezamento, como as observadas nos campos do Pré-sal (Caldeira, 2018), incluindo zonas de acomodação entre as estruturas (Figura 14) (Pereira, 2021). Os dois modelos são compatíveis com o modelo de abertura do segmento central do Atlântico Sul proposto por Heine et al. (2013) e com a abertura da Bacia de Santos associada a um rifte oblíquo.

\section{AGRADECIMENTOS}

À PETROBRAS, por todo o suporte para conciliar trabalho e atividade acadêmica, e ao Departamento de Geologia da Universidade Federal de Ouro Preto (UFOP), pelo apoio e suporte técnico à realização dos estudos.

\section{REFERÊNCIAS}

Adam, J., Urai, J. L., Wieneke, B., Oncken, O., Pfeiffer, K., Kukowski, N., Lohrmann, J., Hoth, S., Van der Zee, W., Schmatz, J. (2005). Shear localisation and strain distribution during tectonic faulting: new insights from granular-flow experiments and high resolution optical image correlation techniques. Journal of Structural Geology, 27(2), 283-301. https://doi.org/10.1016/j.jsg.2004.08.008

Agostini, A., Corti, G., Zeoli, A., Mulugeta, G. (2009). Evolution, pattern and partitioning of deformation during oblique continental rifting: inferences from lithosphericscale centrifuge models. Geochemistry, Geosphysics, Geosystems (GCubed), 10(11), Q11015. https://doi. org/10.1029/2009GC002676

Alves, E. C. (2002). Zonas de fraturas oceânicas e suas relações com a compartimentação tectônica do Sudeste do Brasil. Tese (Doutorado). Rio de Janeiro: Universidade Federal do Rio de Janeiro.

Autin, J., Bellahsen, N., Leroy, S., Husson, L., Beslier, M. O., D'Acremont, E. (2013). The role of structural inheritance in oblique rifting: Insights from analogue models and application to the Gulf of Aden. Tectonophysics, 607, 51-64. https://doi. org/10.1016/j.tecto.2013.05.041

Brune, S., Heine, C., Pérez-Gussinyé, M., Sobolev, V. S. (2014). Rift migration explains continental margin asymmetry and crustal hyperextension. Nature Communications, 5, 4014. https://doi.org/10.1038/ncomms5014
Bubeck, A., Walker, R. J., Imber, J., Holdsworth, R. E., MacLeod, C. J., Holwell, D. A. (2017). Extension parallel to the rift zone during segmented fault growth: Application to the evolution of the NE Atlantic. Solid Earth, 8(6), 11611180. https://doi.org/10.5194/se-8-1161-2017

Caldeira, J. N. M. (2018). Caracterização estrutural da seção Pré-Sal na porção central do Alto Externo da Bacia de Santos, através da análise estrutural de dados sísmicos. Dissertação (Mestrado). Rio de Janeiro: Faculdade de Geologia, Universidade do Estado do Rio de Janeiro.

Carlotto, M. A., Silva, R. C. B., Yamato, A. A., Trindade, W. L., Moreira, J. L. P., Fernandes, R. A. R., Ribeiro, O. J. S., Gouveia Jr., W. P., Carminati, J. P., Qicai, D., Junfeng, Z., Silva-Teles Jr., A. C. (2017). Libra: a newborn giant in the Brazilian Presalt Province. In: R. K. Merril; C. A. Sternbach (Eds.). Gialnt Fields of the Decade 2000-2010, 113, 165176. American Association of Petroleum Geologists. https:// doi.org/10.1306/13572006M1133685

Carminatti, M., Wolff, B., Gamboa, L. (2008). New exploratory frontiers in Brazil. 19th World Petroleum Congress, Madri, Espanha.

Carvalho, T. S. (2017). Cinemática e geometria de camadas rúpteis e dúcteis sobre um sistema de falhas normais reativado: observações a partir de modelos físicos de caixa de areia, departamento de geologia. Dissertação (Mestrado). Ouro Preto: Universidade Federal de Ouro Preto. Disponível em: http://www.repositorio.ufop.br/jspui/ handle/123456789/9354. Acesso em: 18 out. 2021.

Cobbold, P. R., Meisling, K. E., Mount, V. S. (2001). Reactivation of an obliquely rifted margin, Campos and Santos basins, southeastern Brazil. AAPG Bulletin, 85(11), 1925-1944. https:// doi.org/10.1306/8626D0B3-173B-11D7-8645000102C1865D

Corti, G. (2012). Evolution and characteristics of continental rifting: Analog modeling-inspired view and comparison with examples from the East African Rift System. Tectonophysics, 522-523, 1-33. https://doi.org/10.1016/j.tecto.2011.06.010

Corti, G., Cioni, R., Franceschini, Z., Sani, F., Scaillet, S., Molin, P., Isola, I., Mazzarini, F., Brune, S., Keir, D., Erbello, A., Muluneh, A., Illsley-Kemp, F., Glerum, A. (2019). Aborted propagation of the Ethiopian rift caused by linkage with the Kenyan rift. Nature Communications, 10, 1309. https://doi. org/10.1038/s41467-019-09335-2

Corti, G., Wijk, V. J., Cloetingh, S., Morley, K. C. (2007). Tectonic inheritance and continental rift architecture: Numerical and analogue models of the East African Rift system. Tectonophysics, 26(6). https://doi.org/10.1029/2006TC002086 
Del Ventisette, C., Bonini, M., Agostini, A., Corti, G., Maestrelli, D., Domenico, M. (2019). Using different grainsize granular mixtures (quartz and K-feldspar sand) in analogue extensional models. Journal of Structural Geology, 129, 103888. https://doi.org/10.1016/j.jsg.2019.103888

Dunbar, J. A., Sawyer, D. S. (1989). How preexisting weaknesses control the style of continental breakup. Journal of Geophysical Research: Solid Earth, 94(B6), 7278-7292. https://doi.org/10.1029/JB094iB06p07278

Eisenstadt, G., Sims, D. (2005). Evaluating sand and clay models: do rheological differences matter? Journal of Structural Geology, 27(8), 1399-1412. https://doi. org/10.1016/j.jsg.2005.04.010

Faulds, J. E., Varga, R. J. (1998). The role of accommodation zones and transfer zones in the regional segmentation of extended terranes. Geological Society of America Special Papers, 323, 1-45. https://doi.org/10.1130/0-8137-2323-X.1

Fossen, H., Khani, H. F., Faleide, J. I., Ksienzyk, A. K., Dunlap, W. J. (2016). Post-Caledonian extension in the West Norway-northern North Sea region: the role of structural inheritance. Geological Society, London, Special Publications, 439(1), 465-486. https://doi.org/10.1144/SP439.6

Fossen, H., Rotevatn, A. (2016). Fault linkage and relay structures in extensional settings-A review: EarthScience Reviews, 154, 14-28. https://doi.org/10.1016/j. earscirev.2015.11.014

Fossen, H., Schultz, R. A., Rundhovde, E., Rotevatn, A., Buckley, S. J. (2010). Fault linkage and graben stepovers in the Canyonlands (Utah) and the North Sea Viking Graben, with implications for hydrocarbon migration and accumulation. AAPG Bulletin, 94(5), 597-613. https://doi. org/10.1306/10130909088

Gamal, N., Yousef, M., Moustafa, A. R., Bosworth, W. (2021). Spatiotemporal evolution of transfer structures and linked fault systems in an extensional setting: Southwest Gebel Akheider, Cairo-Suez District, Egypt. Marine and Petroleum Geology, 133, 105260. https://doi.org/10.1016/j. marpetgeo.2021.105260

Gamboa, L. A. P., Machado, M. A. P., Silveira, D. P., Freitas, J. T. R., Silva, S. R. P. (2008). Evaporitos estratificados no Atlântico Sul. In: W. U. Mohriak, P. Szatmari, S. Anjos (Eds.). Sal: Geologia e Tectônica. Exemplos nas Bacias Brasileiras, p. 91-163. São Paulo: Beca Edições.
Gerya, T. (2012). Origin and models of oceanic transform faults. Tectonophysics, 522-523, 34-54. https://doi. org/10.1016/j.tecto.2011.07.006

Gibbs, A. D. (1984). Structural evolution of extensional basin margins. Journal of the Geological Society, 141(4), 609-620. https://doi.org/10.1144/gsjgs.141.4.0609

Gomes, P. O., Kilsdonk, B., Grow T., Minken J., Barragn R. (2012). Tectonic evolution of the Outer High of Santos Basin, southern Sao Paulo Plateau, Brazil, and implications for hydrocarbon exploration. In: D. Gao (Ed.). Tectonics and sedimentation: implications for petroleum systems. AAPG Memoir, 100, 125-142. http://dx.doi. org/10.1306/13351550M1003530

Gomes, P. O., Kilsdonk, B., Minken, J., Grow, T., Barragn, R. (2008). The outer high of the Santos Basin, Southern Sao Paulo Plateau, Brazil: pre-salt exploration outbreak, paleogeographic setting, and evolution of the syn-rift structures. AAPG International Conference and Exhibition, Search and Discover, 26-29, Cape Town, Africa do Sul.

Guiraud, M., Buta-Neto, A., Quesne, D. (2010). Segmentation and differential post-rift uplift at the Angola margin as recorded by the transform-rifted Benguela and oblique-toorthogonal-rifted Kwanza basins. Marine and Petroleum Geology, 27(5), 1040-1068. https://doi.org/10.1016/j. marpetgeo.2010.01.017

Heine, C., Zoethout, J., Müller, R. D. (2013). Kinematics of the South Atlantic rift. Solid Earth, 4(2), 215-253. http:// dx.doi.org/10.5194/se-4-215-2013

Heilbron, M., Mohriak, W. U., Valeriano, C. M., Milani, E. J., Almeida, J., Tupinambá, M. (2000). From collision to extension: the roots of the southeastern continental margin of Brazil. In: W. U. Mohriak, M. Talwani (Eds.). Atlantic rifts and continental margins, AGU Geophysical Monograph, 115, 1-32.

Heilbron, M., Valeriano, C. M., Tassinari, C. C. G., Almeida, J., Tupinambá, M., Siga, O., Trouw, R. (2008). Correlation of Neoproterozoic terranes between the Ribeira Belt, SE Brazil and its African counterpart: comparative tectonic evolution and open questions: Geological Society, London, Special Publications, 294(1), 211-237. https:// doi.org/10.1144/SP294.12

Hubbert, M. K. (1937). Theory of scale models as applied to the study of geologic structures. Geological Society of America Bulletin, 48(10), 459-1520. https://doi.org/10.1130/ GSAB-48-1459 
Krantz, R. W. (1991). Measurements of friction coefficients and cohesion for faulting and fault reactivation in laboratory models using sand and sand mixtures. Tectonophysics, 188(12), 203-207. https://doi.org/10.1016/0040-1951(91)90323-K

Kumar, N., Gamboa, L. A. P. (1979). Evolution of the Sao Paulo Plateau (southeastern Brazilian margin) and implications for the early history of the South Atlantic. Geological Society of America Bulletin, 90(3), 281-293. https://doi. org/10.1130/0016-7606(1979)90<281:EOTSPP $>2.0 . C O ; 2$

La Rosa, A., Pagli, C., Keir, D., Sani, F., Corti, G., Wang, H., Possee, D. (2019). Observing Oblique Slip During Rift Linkage in Northern Afar. Geophysical Research Letters, 46(19), 10782-10790. https://doi.org/10.1029/2019GL084801

Larsen, P. (1988). Relay structures in a lower Permian basement-involved extension system, East Greenland. Journal of Structural Geology, 10(1), 3-8. https://doi. org/10.1016/0191-8141(88)90122-8

Macedo, J. M. (1990). Evolução tectônica da Bacia de Santos e áreas continentais adjacentes. In: G. P. Raja Gabaglia, E. J. Milani (Eds.) Origem e evolução de bacias sedimentares. Rio de Janeiro: Petrobras, 361-376.

Maestrelli, D., Montanari, D., Corti, G., Del Ventisette, C., Moratti, G., Bonini, M. (2020). Exploring the interactions between rift propagation and inherited crustal fabrics through experimental modeling. Tectonics, 39(12), e2020TC006211. https://doi.org/10.1029/2020TC006211

Magnavita, L. P., Dehler, N. M., Gomes, L. C., Sant'Anna, M. V., Souza, A. E. C. M., Menezes, J. R. C. (2010). Arcabouço tectônico e cinemática do pré-sal do Sudeste brasileiro. Petrobras, Relatório Reservado, 55.

Mandl, G. (1987). Tectonic deformation by rotation parallel faults: the bookshelf mechanism. Tectonophysics, 141(4), 277-316. https://doi.org/10.1016/0040-1951(87)90205-8

McClay, K. R., Dooley T., Whitehouse, P., Fullarton, L., Charntraprasert, S. (2004). 3D analogue models of rift systems: templates for 3D seismic interpretation. Geological Society, London, Memoirs, 29(1), 101-115. https://doi.org/10.1144/ GSL.MEM.2004.029.01.11

McClay, K. R., Dooley, T., Whitehouse, P., Mills, M. (2002). 4-D evolution of rift systems: Insights from scaled physical models. American Association of Petroleum Geologists Bulletin, 86(6), 935-959. https://doi. org/10.1306/61EEDBF2-173E-11D7-8645000102C1865D
McClay, K. R., Ellis, P. G. (1987). Analogue models of extensional fault geometries. In: M. P. Coward, J. F. Dewey, P. L. Hancock (Eds.). Continental Extensional Tectonics. Geological Society London, Special Publication, 28, 109-125. https://doi.org/10.1144/ GSL.SP.1987.028.01.09

McClay, K. R., Nichols, G. J., Khalil, S., Darwish, M., Bosworth, W. (1998). Extensional tectonics and sedimentation, eastern Gulf of Suez. Egypt. In: B. H. Purser, D. W. J. Bosence (Eds.), Sedimentation and tectonics of rift basins, Red SeaGulf of Aden, 223-238. London: Chapman and Hall. https:// doi.org/10.1007/978-94-011-4930-3_14

Meisling, K. E., Cobbold, P. R., Mount, V. S. (2001). Segmentation of an obliquely rifted margin, Campos and Santos basins, southeastern Brazil. AAPG Bulletin, 85(11), 1903-1924. https://doi. org/10.1306/8626D0A9-173B-11D7-8645000102C1865D

Minzoni, M., Cantelli, A., Thornton, J. (2019). Seismic-scale geometries and sequence-stratigraphic architecture of early Cretaceous Syn-Post Rift Lacustrine Carbonate Systems, Pre-Salt Section, South Atlantic Margins. In: B. Hart, N. C. Rosen, D. West, A. D'Agostino, C. Messina, M. Hoffman, R. Wild (Eds.). Sequence stratigraphy: the future defined. https://doi.org/10.5724/gcs.17.193

Mohriak, W. U. (2003). Bacias sedimentares da margem continental brasileira. In: L. A. Bizzi, C. Schobbenhaus, R. M. Vidotti, J. H. Gonçalves (eds.). Geologia, tectônica e recursos minerais do Brasil, 87-165. Brasil: Serviço Geológico do Brasil - CPRM.

Mohriak, W. U., Rosendahl, B. R., Turner, J. P., Valente, S. C. (2002). Crustal architecture of South Atlantic volcanic margins, In: M. A. Menzies, S. L. Klemperer, C. J. Ebinger, J. Baker (Eds.), Volcanic Rifted Margins. Special Paper Geological Society of America, 362, 159-202. https://doi. org/10.1130/0-8137-2362-0.159

Moreira, J. L. P., Madeira, C. V., Gil, J. A., Machado, M. A. P. (2007). Bacia de Santos. Boletim de Geociencias da Petrobras, 15(2), 531-549.

Morgan, J. P., Taramón, J. M., Araujo, M., Hasenclever, J., Perez-Gussinye, M. (2020). Causes and consequences of asymmetric lateral plume flow during South Atlantic rifting. Proceedings of the National Academy of Sciences of the United States of America, 117(45), 27877-27883. https:// doi.org/10.1073/pnas.2012246117 
Morley, C. K. (1995). Developments in the structural geology of rifts over the last decade and their impact on hydrocarbon exploration. In: J. J. Lambiase (Ed.). Hydrocarbon habitat in rift basins, 80(1), 1-32. Geological Society of London, Special Publication. https://doi.org/10.1144/GSL.SP.1995.080.01.01

Morley, C. K., Nelson, R. A., Patton, T. L., Munn, S. G. (1990). Transfer zones in the East African rift system and their relevance to hydrocarbon exploration in rifts. AAPG Bulletin, 74(8), 1234-1253. https://doi. org/10.1306/0C9B2475-1710-11D7-8645000102C1865D

Moulin, M.,Aslanian, D., Unternehr, P. (2010). Anew starting point of the south and equatorial Atlantic Ocean. Earth Sciences Reviews, 98(1-2), 1-37. https://doi.org/10.1016/j.earscirev.2009.08.001

Nixon, C. W., Vaagan, S., Sanderson, D. J., Gawthorpe, R. L. (2019). Spatial distribution of damage and strain within a normal fault relay at Kilve, U.K. Journal of Structural Geology, 118, 194-209. https://doi.org/10.1016/j.jsg.2018.10.016

Peacock, D. C. P., Knipe, R. J., Sanderson, D. J. (2000). Glossary of normal faults. Journal of Structural Geology, 22(3), 291-305. https://doi.org/10.1016/S0191-8141(00)80102-9

Peacock, D. C. P., Sanderson, D. J. (1991). Displacements, segment linkage and relay ramps in normal fault zones. Journal of Structural Geology, 13(6), 721-733. https://doi. org/10.1016/0191-8141(91)90033-F

Pereira, C. E. L. (2021). Modelagem física analógica de rifteamento oblíquo: a influência de estruturas preexistentes na formação do pré-sal da Bacia de Santos, Brasil. Dissertação (Mestrado). Ouro Preto: Universidade Federal de Ouro Preto. Disponível em: http://www.repositorio.ufop.br/jspui/ handle/123456789/13205. Acesso em: 19 out. 2021.

Pereira, M. J., Macedo, J. M. (1990). A Bacia de Santos: perspectivas de uma nova província petrolífera na plataforma continental sudeste brasileira. Boletim Geociências da Petrobras, 4, 3-11.

Pinto, L., Muñoz, C., Nalpas, T., Charrier, R. (2010). Role of sedimentation during basin inversion in analogue modelling. Journal of Structural Geology, 32(4), 554-565. https://doi. org/10.1016/j.jsg.2010.03.001

Quirk, G. D., Hertle, M., Jeppesen, J., Raven, M., Mohriak, U. W., Kann, D. J, Norgaard, M., Howe, M. J., Hsu, D., Coffey, B., Mendes, M. P. (2013). Rifting, subsidence and continental break-up above a mantle plume in the central South Atlantic. Geological Society of London, Special Publications, 369(1), 185-214. https://doi.org/10.1144/SP369.20
Rigoti, C. A. (2015). Evolução tectônica da Bacia de Santos com ênfase na geometria crustal: interpretação integrada de dados de sísmica de reflexão e refração, gravimetria e magnetometria. Dissertação (Mestrado). Rio de Janeiro: Universidade do Estado do Rio de Janeiro.

Ring, U. (1994). The influence of preexisting structure on the evolution of the Cenozoic Malawi rift (East African rift system). Tectonics, 13(2), 313-326. https://doi. org/10.1029/93TC03188

Ros, E., Pérez-Gussinyé, M., Araújo, M., Romeiro, T., Andrés-Martínez, M., Morgan, J. P. (2017). Lower crustal strength controls on melting and serpentinization at magmapoor margins: potential implications for the South Atlantic. Geochemistry, Geophysics, Geosystems, 18(12), 4538-4557. https://doi.org/10.1002/2017GC007212

Rosendahl, B. R. (1987). Architecture of continental rifts with special reference to East Africa. Annual Review of Earth and Planetary Sciences, 15, 445-503. https://doi. org/10.1146/annurev.ea.15.050187.002305

Sandwell, D. T., Smith, W. H. F. (2009). Global marine gravity from retracked Geosat and ERS-1 altimetry: Ridge segmentation versus spreading rate. Journal of Geophysical Research: Solid Earth, 114(B1), 1-18. https:// doi.org/10.1029/2008JB006008

Schellart, W. P. (2000). Shear test results for cohesion and friction coefficients for different granular materials: scaling implications for their usage in analogue modelling. Tectonophysics, 324(1-2), 1-16. https://doi.org/10.1016/ S0040-1951(00)00111-6

Schlische, R. W., Withjack, M. O., Eisenstadt, G. (2002). An experimental study of the secondary deformation produced by oblique-slip normal faulting. AAPG Bulletin, 86(5), 885-906. https://doi. org/10.1306/61EEDBCA-173E-11D7-8645000102C1865D

Schmitt, R. S., Trouw, R., Van Schmus, W. R., Armstrong, R., Stanton, N. S. G. (2016). The tectonic significance of the Cabo Frio Tectonic Domain in the SE Brazilian margin: a Paleoproterozoic through Cretaceous saga of a reworked continental margin. Brazilian Journal of Geology, 46(Suppl. 1), 37-66. https://doi.org/10.1590/2317-4889201620150025

Scholz, C. A., Shillington, D. J., Wright, L. J. M., Accardo, N., Gaherty, J. B., Chindandali, P. (2020). Intrarift fault fabric, segmentation, and basin evolution of the Lake Malawi (Nyasa) Rift, East Africa. Geosphere, 16(5), 1293-1311. https://doi.org/10.1130/GES02228.1 
Stanton, N., Kusznir, N., Gordon, A., Schmit, R. (2019). How inheritance and magmatism influence rifted margins A case study of the Campos Basin (Brazil). 6th International Congress of the Brazilian Geophysical Society, 1-4. https:// doi.org/10.22564/16cisbgf2019.190

Szatmari, P., Milani, E. J. (2016). Tectonic control of the oil-rich large igneous-carbonate-salt province of the South Atlantic rift. Marine and Petroleum Geology, 77, 567-596. https://doi.org/10.1016/j.marpetgeo.2016.06.004

Taylor, B., Weiss, J. R., Goodliffe, A. M., Sachpazi, M., Laigle, M., Hirn, A. (2011). The structures, stratigraphy and evolution of the Gulf of Corinth rift, Greece. Geophysical Journal International, 185(3), 1189-1219. https://doi. org/10.1111/j.1365-246X.2011.05014.x

Tommasi, A., Vauchez, A. (2001). Continental rifting parallel to ancient collisional belts: an effect of the mechanical anisotropy of the lithospheric mantle. Earth and Planetary Science Letters, 185(1-2), 199-210. https://doi.org/10.1016/ S0012-821X(00)00350-2

Torsvik, T. H., Rousse, S., Labails, C., Smethurst, M. A. (2009). A new scheme for the opening of the South Atlantic Ocean and the dissection of an Aptian salt basin. Geophysical Journal International, 177(3), 1315-1333. https://doi. org/10.1111/j.1365-246X.2009.04137.x

Trudgill, B., Cartwright, J. (1994). Relay-ramp forms and normal-fault linkages, Canyonlands National Park, Utah. Geological Society of America Bulletin, 106(9), 1143-1157. https://doi.org/10.1130/0016-7606(1994)106<1143:RRFA $\mathrm{NF}>2.3 . \mathrm{CO} ; 2$

Van Gent, H. W., Holland, M., Urai, J. L., Loosveld, R. (2010). Evolution of fault zones in carbonates with mechanical stratigraphy: insights from scale models using layered cohesive powder. Journal of Structural Geology, 32(9), 1375-1391. https://doi.org/10.1016/j.jsg.2009.05.006
Vendeville, B., Cobbold, P. R., Davy, P., Brun, J. P., Choukroune, P. (1987). Physical models of extensional tectonics at various scales. In: M. P. Coward, J. F. Dewey, P. L. Hancock (Eds.). Continental extensional tectonics. Geological Society of London, Special Publications, 28(1), 95-107. https://doi.org/10.1144/GSL.SP.1987.028.01.08

Weijermars, R., Schmeling, H. (1986). Scaling of Newtonian and non-Newtonian fluid dynamics without inertia for quantitative modelling of rock flow due to gravity (including the concept of rheological similarity). Physics of the Earth and Planetary Interiors, 43(4), 316-330. https://doi.org/10.1016/0031-9201(86)90021-X

Zhang, S., Chang, S., Huang, H., Dong, Y., Shen, Y., Luo, Y., Zhu, B. (2020). Prediction of favorable carbonate reservoirs under extremely thick salts via poststack facies-controlled and prestack zoeppritz equation inversions in the Santos Basin of Brazil. Hindawi Geofluids, 2020, 6205185. https:// doi.org/10.1155/2020/6205185

Zhong, X., Escalona, A. (2020). Evidence of rift segmentation and controls of Middle to late jurassic synrift deposition in the ryggsteinen ridge area, Northern North Sea. AAPG Bulletin, 104(7), 1531-1565. https://doi.org/10.1306/03172018173

Zwaan, F., Schreurs, G. (2017). How oblique extension and structural inheritance influence rift segment interaction: Insights from 4D analog models. Interpretation, 5(1), SD119-SD138, https://doi.org/10.1190/INT-2016-0063.1

Zwaan, F., Schreurs, G., Adam, J. (2018). Effects of sedimentation on rift segment evolution and rift interaction in orthogonal and oblique extensional settings: Insights from analogue models analysed with 4D X-ray computed tomography and digital volume correlation techniques. Global and Planetary Change, 171, 110-133. https://doi. org/10.1016/j.gloplacha.2017.11.002

Zwaan, F., Schreurs, G., Naliboff, J., Buiter, S. J.H. (2016). Insights into the effects of oblique extension on continental rift interaction from 3-D analogue and numerical models. Tectonophysics, 693(Parte B), 239-260. https://doi.org/10.1016/j.tecto.2016.02.036 